\title{
The Chemical Conversion of Biomass-Derived Saccharides: an Overview
}

\author{
Jean Marcel R. Gallo*,a and Marilia A. Trapp ${ }^{b}$ \\ ${ }^{a}$ Grupo de Energia Renovável, Nanotecnologia e Catálise (GreenCat), Departamento de Química, \\ Universidade Federal de São Carlos, Rodovia Washington Luis, $\mathrm{km} 235$, \\ CP 676, 13565-905 São Carlos-SP, Brazil \\ ${ }^{b}$ Max Planck Institute for Chemical Ecology, Hans-Knöll-Straße 8, D-07745 Jena, Germany
}

\begin{abstract}
Chemicals commodities and consumable, accounting for billions of ton of carbon per year, are produced in an industry based on non-renewable fossil feedstocks. Oil reserves are enough for feeding chemical industry for another century, and therefore, it is essential finding alternative sources of carbon for a progressive replacement of the industrial feedstock. In this context lignocellulosic, a renewable source of carbon composed mainly by polymers of sugars, appears as the most promising candidate. Herein, it will be discussed the status, challenges and prospective future of biomass as industrial feedstock in a raising biorefinery, aiming to clarify the real problems in the actual biomass processing. It will be shown that lignocellulosic biomass is able to replace oil in the production of several chemicals and also delivery new compounds with important applications. However, for a cost effective use of biomass, the development and improvement of solvent and catalytic systems play a leading role. The sustainability of biomass feedstock is also discussed from the economical, social and environmental points of view.
\end{abstract}

Keywords: biomass conversion, lignocellulosic biomass, biorefinery, catalysis, sustainability

\section{Introduction}

In the XX century, technology developed in an unprecedented speed, introducing outstanding advances and new products. Along with the technology, life style has also changed and industry had to be adapted to a growing population with higher purchasing power and new needs. Efficient refineries and petrochemical manufacturing units have been essential for supplying the industry with chemicals and providing the fuels for energy and transportation. Indeed, fuel is the major petroleum-derived product (Figure 1A) and the industrial and economical grown are only possible due to the ability of industry in obtaining fuel at high productivity and low cost.

For instance, the consumption of gasoline has been systematically rising along with the number of car. In Brazil, the number of automobiles per 1000 habitants increased from 107 in 1998 to 244 in 2015 (data from the Brazilian National Department of Traffic and the Brazilian Institute of Geography and Statistics. They were not available prior to 1998). In the USA, the number increased from 545 in 1970 to 888 in 2013. ${ }^{1}$ For these two

*e-mail: jean@ufscar.br

countries, the approximate gasoline consumption in 2014 was, respectively, 41 and 530 billion of liters. Interestingly, fuel for light vehicles represent $59 \%$ of all the consumed fuel in the USA (Figure 1B), and most of it is used in private and family cars for people to go to work and perform their daily errands.

(A)

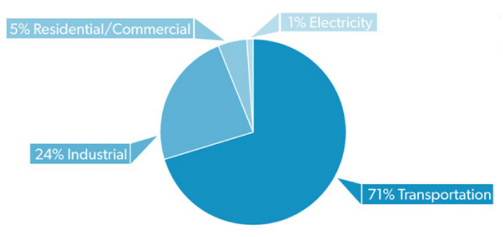

Figure 1. (A) USA petroleum consumption by sector ${ }^{2}$ and (B) transportation energy use by mode in $2012 .^{3}$

Besides fuels, $24 \%$ of all petroleum consumption is employed as industrial chemical input for the production of medicines, chemicals, polymers, detergents, fibers, etc. (Figure 2). For instance: the production of the two popular medicines paracetamol (acetaminophen) and salicylic acid reaches, respectively, approximately 15 and 89 thousand metric tons per year; ${ }^{4}$ detergents are produced at a scale of 13 million ton per year (2006 data); ${ }^{5}$ and polymers (or 


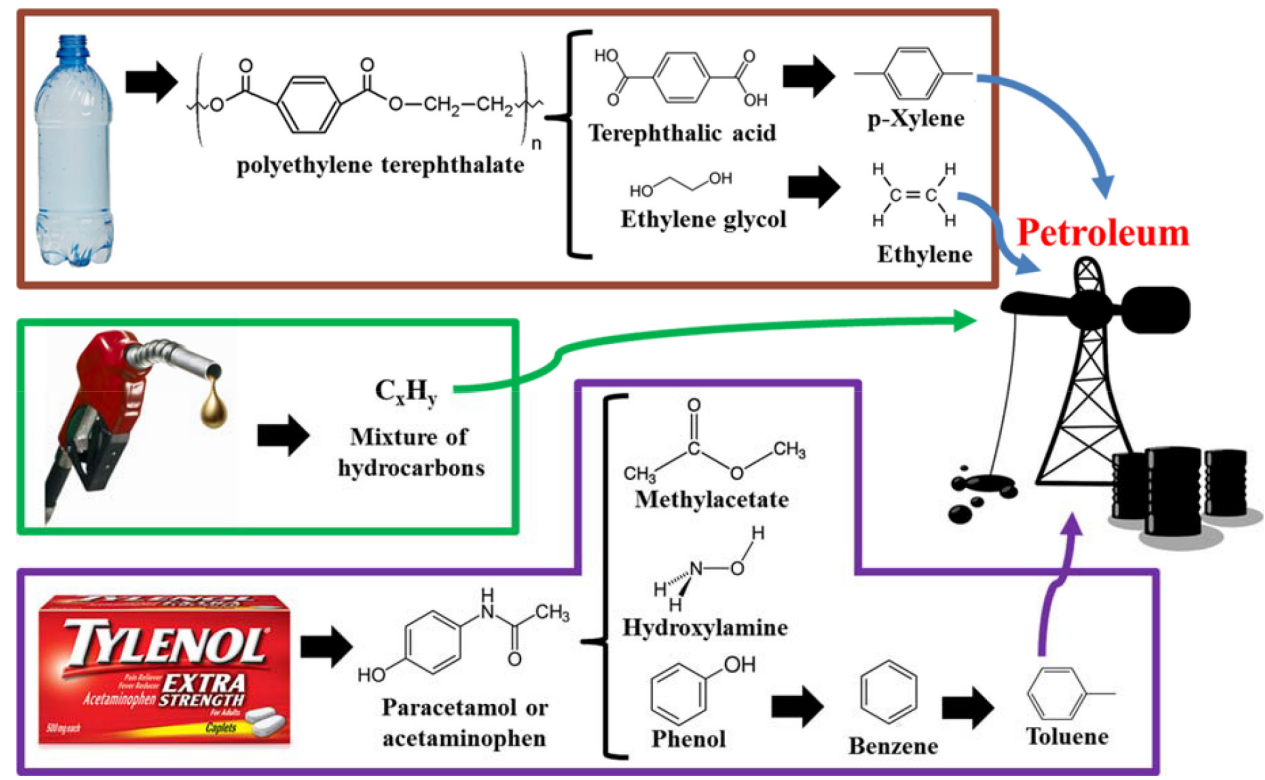

Figure 2. Examples on how plastics, fuels and medicines can be derived from petroleum. For sake of brevity, not all reaction steps are shown.

plastics) production reached 311 million metric tons in $2014{ }^{6}$

Therefore, the production of petroleum must be large enough to provide, for instance, billions of liters of fuel, millions of tons of detergents and plastics and thousands of tons of medicines. Current industry has been consistent enough to address new and old needs of a growing society, which would be impossible without an efficient extraction, management and chemical modification of petroleum. Indeed, modern life, as we know it, relies on petroleum and, therefore, it is not surprising that the consumption of oil-derives have reached high rates in developed and underdevelopment countries. In Brazil and in the USA, the daily per capita oil consumption is respectively 7.1 and $9.5 \mathrm{~L}$, while the worldwide average is approximately $2 \mathrm{~L} ., 8$

It is alarming, however, that the whole industry is mainly based on non-renewable sources of carbon and the known oil reserves would be enough to feed the actual demand for no longer than 70-130 years. ${ }^{9}$ This number is already taking in consideration the use of petroleum from less reachable areas (such as the pre-salt layer petroleum) and heavier oils (the Venezuelan, for example), which implies in a less sustainable and more expensive petroleum extraction and processing. Furthermore, only 10 countries are responsible for over $60 \%$ of the petroleum production, and as the reserves decrease, petroleum may be used as a "bargaining chip" in international political and economic decisions. In the 1970's, this type of scenario motivated Brazil to implement of ProAlcohol (bioethanol) and ProOleo (biodiesel) programs,${ }^{10}$ which aimed to stimulate the development of new sources of energy, as well as their production and consumption.
Although it is clear that an alternative for petroleum is necessary, the changes in chemical industry structure do not come overnight. Therefore, governments, academia and industry have been proposing long term researches to identify reliable and renewable alternative carbon, which can to feed chemical industry with the same products obtained from oil, or at least, different compounds, but with the same applications. In this critical account, the use of biomass as feedstock for biorefineries will be presented and discussed. Herein, the aim is not delivery a literature review, but presenting an overview of status and challenges on chemical conversion of vegetal feedstocks using examples from the literature.

\section{Lignocellulosic Biomass and Chemical Conversion of Biomass Saccharide Fraction}

No matter how different plants look, smell or taste, they all have something in common: most of their composition comes from cellulose, hemicellulose and lignin. And this is also valid for the different parts of the plant, such as the stalk, leaf and flower. Cellulose (the major component of biomass) is formed by a crystalline polymer of the monosaccharide glucose, while hemicellulose is a polymer of several monosaccharides, but predominantly, the pentose xylose. Lignin, on the other hand, is a polymer of the phenolic units conideryl, coumaryl and syringyl alcohols (Figure 3). With such simple and regular composition, lignocellulosic biomass appears as the most promising renewable carbon source alternative for petroleum. In an applied fashion, sugar cane and corn have been the most used sources of biomass for 

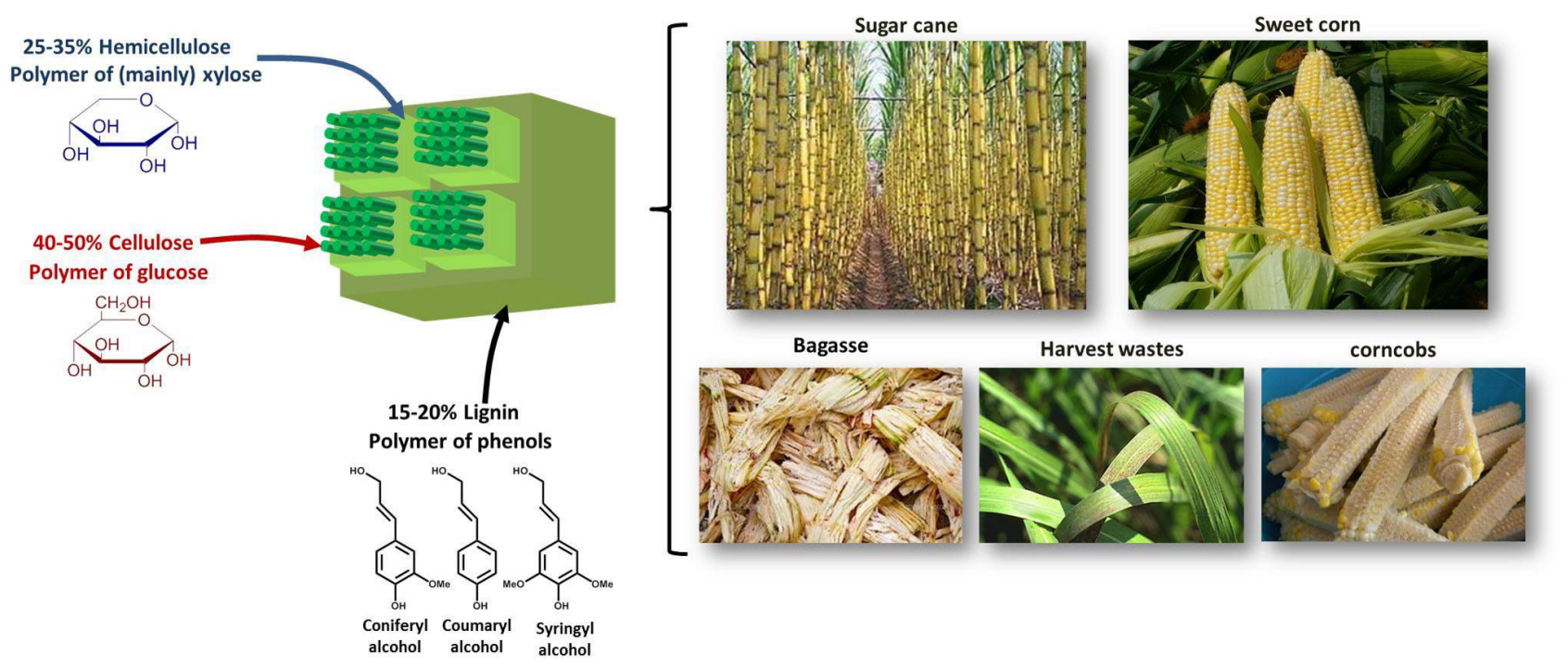

Figure 3. Lignocellulosic biomass sources and major composition.

producing chemicals, and nearly any part of these plants can be used (Figure 3).

So, while petroleum is composed mainly by long chain hydrocarbons, biomass is highly functionalized; glucose, for example, has one oxygen atom for each carbon atom. Therefore, the production of fuel and industrial chemicals out of these two feedstocks follows different processing routes (Figure 4). Fuels, for example, are hydrocarbons with a defined range of molecular weight. Hence, the fuel fraction of petroleum can be separated by distillation and enriched through chemical reactions for molecular weight adjusting (such as reforming, alkylation and cracking). However, for production of chemicals, the hydrocarbons obtained from petroleum must be functionalized through high energy-consuming processes.

In biorefineries, on the other hand, the feedstock presents a polymeric nature, and therefore, the first step involves cracking, chemical or thermo depolymerization. However, for production of fuels, the highly functionalized intermediates must have their molecular weight adjusted and be completely defunctionalized into hydrocarbon, which seems to demand more energy and chemical modification compared to the fuel production from petroleum. Contrarily, biomass has an advantage over petroleum for synthesis of functionalized chemicals: it is already functionalized. Therefore, the chemical processes involve only the optimization of functional group type and the functionalization degree.

Although the vegetal feedstock is different from the fossil one, it is fundamental for biorefineries to be able to integrate themselves to chemical industry as well as the refinery/petrochemical industry do. Therefore, it is important to analyze and discuss the chemical potentiality and limitations of the biomass feedstock and understand

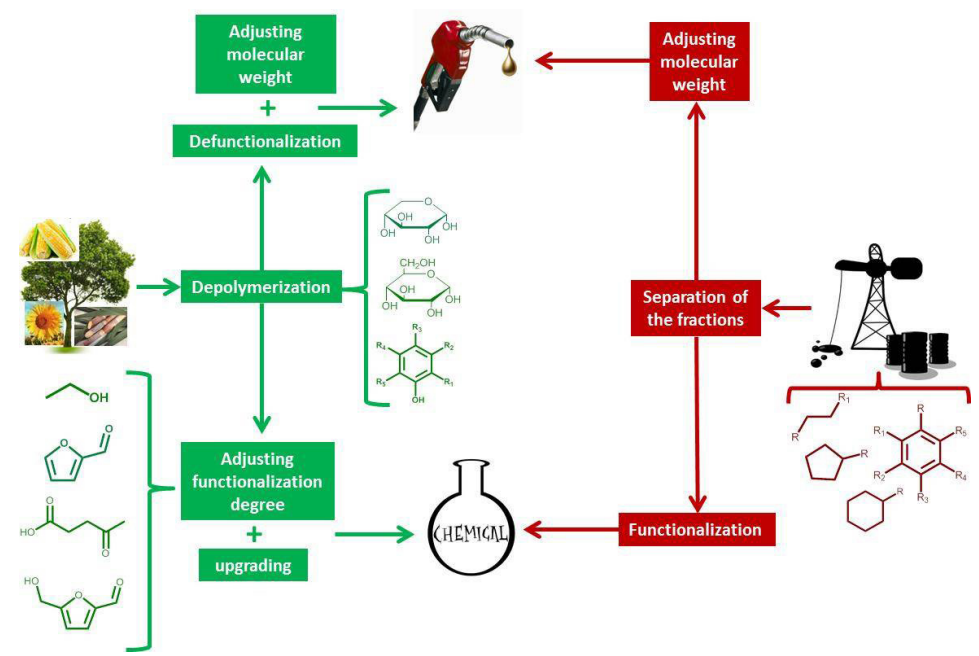

Figure 4. Comparison between the production of chemicals and fuels from petroleum and lignocellulosic biomass. 
what type of products it can delivery to the chemical industry.

As shown in Figure 3, the saccharide fraction accounts for up to $85 \%$ of the biomass composition and are present in a polymeric form: cellulose and hemicellulose. Transforming these sugar polymers into chemicals can be performed though several routes, including chemical, thermal, and biological. In this account, the chemical and catalyzed conversion of the saccharide fraction of biomass will be the focus of the discussion.

Classically, the first step in biomass chemical conversion involves the cellulose or hemicellulose depolymerization by acid catalyzed hydrolysis into the correspondent monosaccharides, which are well established and standardized procedures. ${ }^{11}$ As mentioned before, cellulose hydrolysis yields glucose and hemicellulose leads to mainly xylose. The transformation of these monosaccharides into chemicals can begin with dehydration, oxidation or reduction reactions. In this way, the acid catalyzed dehydration has been the most studied and well-established process (Figure 5).

Under acid conditions, glucose is dehydrated to 5-hydroxymethylfurfural (HMF), which can be subsequently hydrolyzed to levulinic acid (LA) and formic acid. Xylose and other natural pentoses (such as arabinose and ribose) are dehydrated by acid catalysis to furfural. Alternatively, the reduction of glucose and xylose leads, respectively, to sorbitol and xylitol, while the oxidation yields gluconic acid (and saccharic acid) and xylonic acid (and xylaric acid). These primary products of monosaccharides chemical conversion do not have direct large-scale application, but in the context of biorefinery, they can be intermediates for production of important chemicals, and therefore, they are known as platform molecules. Indeed, HMF, furfural, levulinic acid, xylitol and sorbitol were listed as the most important bio-based platform molecules obtained from chemical conversion of carbohydrates (the other compounds in the list are biochemically obtained). ${ }^{12}$

The potentiality of the platform molecules is related to their flexibility to be transformed in a broad range of chemicals with relevant application. In order to illustrate this potentiality, some examples of chemical molecules that are obtained from the catalyzed conversion of saccharidederived platform molecules are shown in Figure 6 .

For instance, HMF can be selectively hydrogenated with a $\mathrm{Ru} / \mathrm{CeO}_{\mathrm{x}}$ catalyst to yield dihydroxymethyltetrahydrofuran, a precursor for solvents and monomers. ${ }^{13} \mathrm{Using} \mathrm{CuRu} / \mathrm{C}$ catalyst, HMF can also provide the fuel additive 2,5-dimethylfuran (DMF). ${ }^{14}$ Additionally, DMF can undergo Diels-Alder reaction with ethylene to form $p$-xylene ${ }^{15-18}$ (an important chemical classically obtained from petroleum in the benzene, toluene and xylenes-BTX-mixture). Brønsted

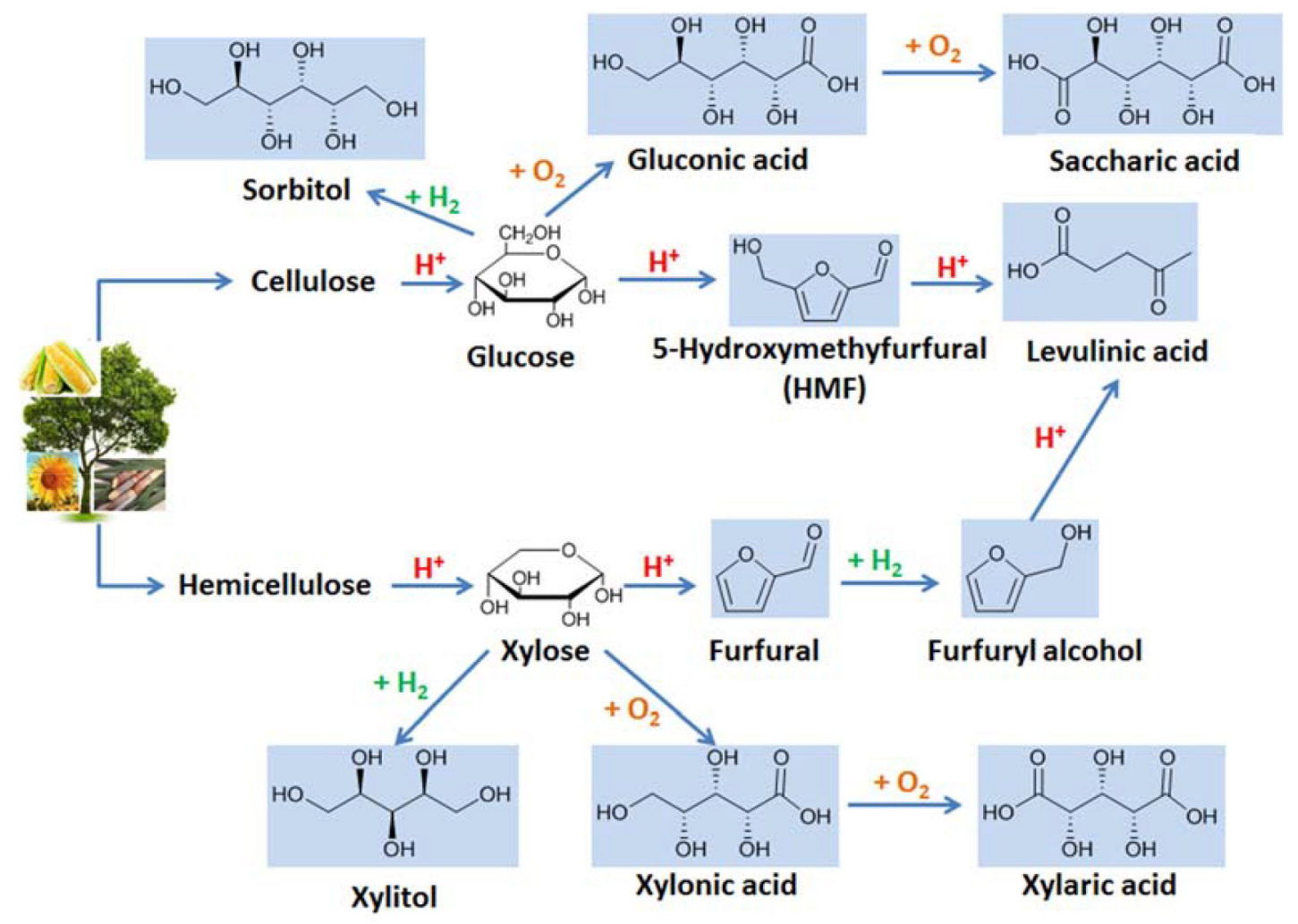

Figure 5. Cellulose and hemicellulose hydrolysis and the subsequent conversion of the monosaccharides into platform molecules (blue background). 


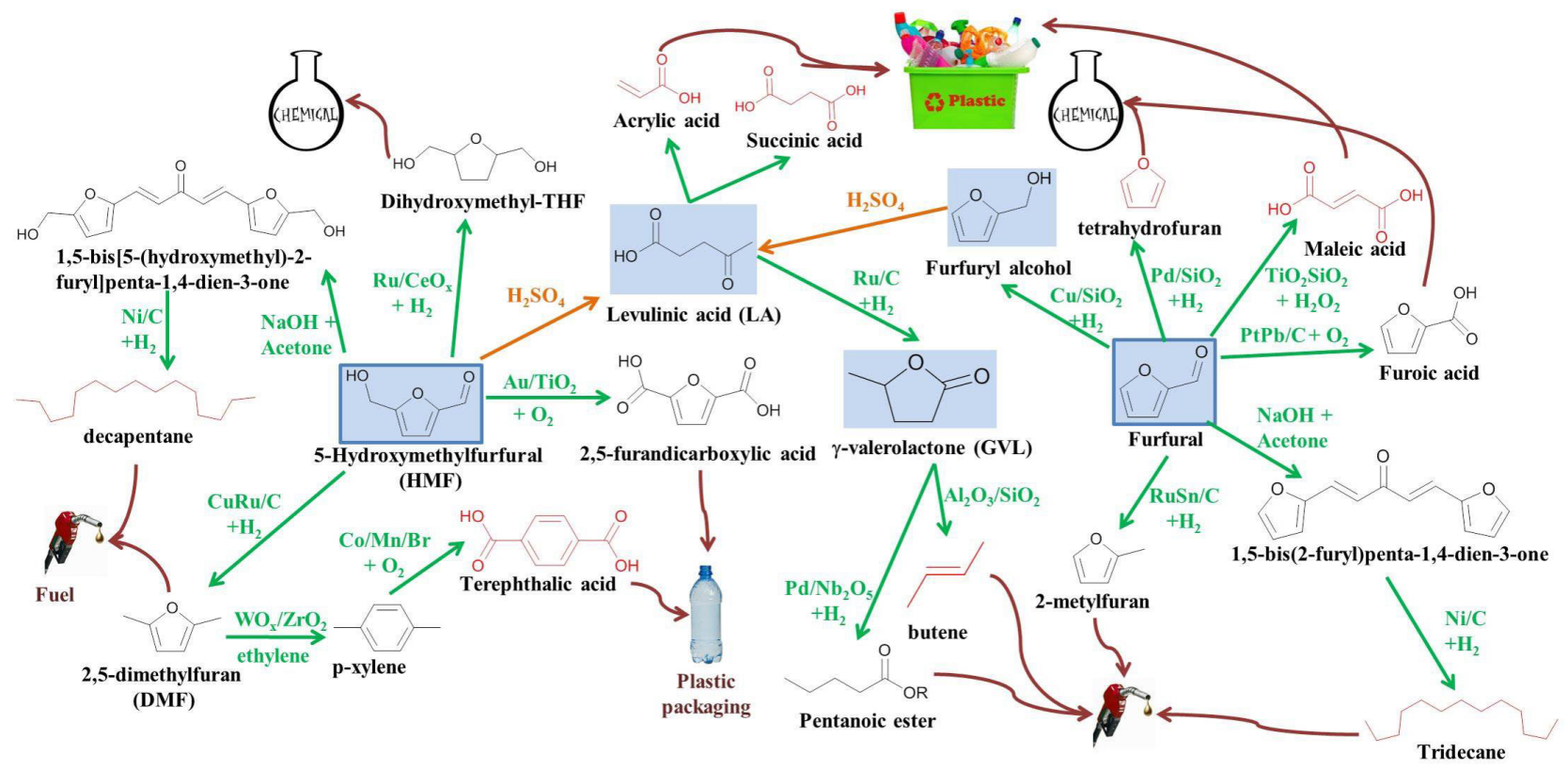

Figure 6. Some of the products obtained from platform molecules (blue background) and their potential applications. In red, molecules also commercially obtained from non-renewable feedstocks. Orange arrows show the reaction pathway that integrates the cellulose and hemicellulose reaction pathways.

acid $\mathrm{ZSM}-5,{ }^{18} \mathrm{WOx} / \mathrm{ZrO}_{2}$ containing both Lewis and Brønsted acid sites, ${ }^{19}$ and pure Lewis acid Sn-Beta and $\mathrm{Zr}$-Beta zeolites ${ }^{16}$ have shown to be active catalysts for this reaction. Commercially, $p$-xylene is oxidized to terephthalic acid and then used (along with ethyleneglycol) for the production of the polyethyleneterephthalate (PET), which is commonly used to produce packaging.

Alternatively, HMF can be oxidized with platinum, palladium and gold-based catalysts into 2,5-furandicarboxylic acid (FDCA), a bio-based monomer that can accordingly replace terephthalic acid in the production of polymers. ${ }^{19-22}$ For instance, polyethylene furanoate (PEF), a copolymer from FDCA and ethyleneglycol, is an alternative for the non-renewable polyethylenetherephthalate (PET) in the manufacture of bottles and other packaging. PEF polymer has also improved properties for packing and bottles applications compared to PET, such as: lower permeability to water, oxygen, and carbon dioxide (which guarantees the quality and freshness of the product for longer time); and better thermal and mechanical properties, allowing a broader range of application. ${ }^{23}$ These examples build a particularly interesting story: HMF can be transformed into chemicals, which are currently obtained from petroleum such as terephthalic acid, or yet, a new chemical, such as FDCA, that can replace the terephthalic acid. Therefore, the implementation of a biorefinery does not imply in a complete change on chemical industry.

Besides being an promising polymer, FDCA can also be converted, though reduction, to adipic acid, an important monomer for the production of Nylon. ${ }^{24}$ However, a more interesting route for production of adipic acid would involve the reduction of glucaric acid, which can be obtained by the direct oxidation of glucose..$^{24,25} \mathrm{Pt}$ catalysts have shown to be efficient for production of glucaric acid, however, the following step to adipic acids is still challenging. ${ }^{24,25}$

Since cellulose is the major component in biomass, its reaction roadmap was thoroughly studied; therefore, connecting cellulose and hemicellulose reaction roadmaps is particularly interesting. The common species in both roadmaps is the levulinic acid (LA) (Figure 6, orange arrows), which can be produced from hemicellulose, by hydrogenation of furfural to furfuryl alcohol that is then hydrolyzed to LA. However, handling furfuryl alcohol is complicated, since it is extremely reactive to polymerization under temperature, light and acid catalysis conditions. LA can be also produced directly from cellulose, which is significantly simpler and only requires acid catalysis. ${ }^{26}$

The chemical conversion of LA to $\gamma$-valerolactone (GVL), another chemical platform, has been extensively studied. ${ }^{27-30}$ GVL can be converted to fuel precursors, such as butenes, higher hydrocarbons and pentanoic acid. ${ }^{31-43}$ Although the focus of this account is on the chemical conversion, it is worth to mention that several reaction are only possible with high productivity through biocatalysis, as for example, the conversion of LA to acrylic, succinic acid and lactic acid. Recently, it has been shown that lactic acid esters can be directly obtained from biomass-derived sugars by retroaldol condensation using Lewis acid catalysts. ${ }^{44-47}$

Furfural can also be converted to important dropin chemicals (those usually obtained from petroleum) 
such as tetrahydrofuran (industrial solvent and chemical intermediate) by decarbonylation with $\mathrm{Pd} / \mathrm{SiO}_{2}{ }^{48}$ and maleic acid (precursor for resins) by oxidation with titanium silicalite as catalyst and hydrogen peroxide as oxidizing agent. ${ }^{49}$ Aerobic oxidation of furfural with $\mathrm{PtPb}$ based catalysts leads to furoic acid, ${ }^{50}$ an precursor for chemical and pharmaceutical industry. ${ }^{51}$ Both HMF and furfural can undergo base or acid catalyzed aldol condensation with ketones and aldehydes to yield larger molecules, which can be fully hydrogenated to fuel-range hydrocarbons. ${ }^{52-56}$

The aforementioned processes are just some of many examples that prove how significant platform molecules produced from cellulose and hemicellulose can be as alternatives for fossil-based processes and products. It is noticeable that most of the biomass derived molecules are based on furans (Figure 6), or 5-6-carbon acyclic compounds. Obtaining aromatics from saccharide-derived compounds depends mainly on the Diels-Alder reaction between furans and ethylene. Aromatics are highly important intermediates in the chemical industry, and classically obtained in refineries as the so called BTX (benzene, toluene and xylenes). Although the research on Diel-Alder of furans for the production of aromatics has been intensified in the last few years, ${ }^{57-62}$ this chemical route is too expensive and energy demanding to become commercial. As it regards the production of aromatics, lignin is the most promising feedstock..$^{63}$ The chemical depolymerization of lignin can lead to a broad range of compounds containing phenolic compounds, ${ }^{64}$ which can be further upgraded for the production of alkylphenols, ${ }^{65}$ phenols ${ }^{65}$ arenes, ${ }^{66}$ defunctionalized aromatics, ${ }^{67,68}$ and, ultimately, the BTX compounds..$^{67-70}$

\section{Solvent Effect: More than Only Dissolving}

In a chemical process, there is no perfect solvent. Separating the product from the solvent, as well as, purifying, reusing or disposing the solvent will always add costs to the process. From the sustainability (and also green chemistry) point of view, the best approach would be using no solvent, however, many liquid phase reactions need a solvent either because the reactants are solid, or because the reaction performance is improved.

Water is the first option as solvent, since it is cheap and can be safely disposed. The conversion of monosaccharides can indeed be performed in water. However, the product yields are systematically low. Taking as an example the synthesis of HMF from the dehydration of fructose, a typical HMF yield in water is lower than $30 \% .^{71-74}$ However, using aprotic solvents, such as dimethylsulfoxide $(\mathrm{DMSO})^{75-78}$ and GVL, ${ }^{73,74}$ side reactions are suppressed, and HMF yields higher than $90 \%$ are expected using mineral acids as catalysts.

The separation of the product from these high boiling point solvents is a challenge, mainly, because HMF is prone to decomposition and polymerization at high temperature. Ionic liquids ${ }^{79,80}$ or ionic liquids-like ${ }^{81}$ systems also lead to an outstanding HMF productivity, however, once again separation and isolation of the product is an issue. Furthermore, ionic liquids are expensive and deactivated in the presence of water (reaction byproduct, besides water is inherently wet).

HMF at high yields was produced using a biphasic solvent system formed by: (i) an aqueous and (ii) an organic extracting layer. Although the chemical reaction takes place in the aqueous phase, once formed, HMF is extracted to the organic layer and then preserved from degradation. ${ }^{71,72}$ Although the biphasic system is an improvement towards the solvent systems using water, ionic liquids, and high boiling point solvents, it also presents several drawbacks: (i) an efficient stirring is required to assure the mixing of both phases, which is an issue in large scale; (ii) the organic extracting phase efficiency is questionable, since a significant amount of HMF remains in the aqueous phase; (iii) improved extracting efficiency of the organic layer can be obtained when using some high-boiling point toxic solvent; ${ }^{82}(i v)$ the aqueous layer is saturated with salt, and therefore, incompatible with heterogeneous catalysts, since the salt cation would ion-exchange with the proton in the solid catalyst surface, leading to homogeneous catalysis. ${ }^{74}$ The later statement is one to be carefully taken in account when aiming to develop an efficient and sustainable process for biomass conversion. Switching from homogeneous to heterogeneous catalysis represents an important breakthrough in this field, and the solvent system has to follow this trend.

In the context of biorefinery, ideally, biomass-derived solvents with low toxicity should be preferred, and good hints on possible aprotic biomass derived solvents are shown in Figure 6: furans and lactones, such as tetrahydrofuran (THF), methyltetrahydrofuran (MTHF), DMF and GVL. Although monosaccharides are not soluble in these solvents, the addition of small amounts of water (except for DMF, not miscible with water) allows sugar solubility and the formation of a single-phase solvent system. Furthermore, the conversion of fructose in GVL (and other lactones) and THF have optimal performance when 10-20 wt.\% of water is used as a co-solvent. ${ }^{73} \mathrm{In}$ monophasic solvent system (composed by GVL or THF containing $10 \mathrm{wt} . \%$ of water), the conversion of fructose into HMF has a similar selectivity to biphasic solvent systems and comparable with the DMSO and ionic liquids 
systems $(>80 \%) \cdot{ }^{73}$ Furthermore, it has been shown that in the monophasic system, homogeneous catalysts can be replaced by heterogeneous ones without compromising the HMF selectivity. ${ }^{73}$ Alcohols can also be used as a solvent for fructose conversion under acid catalyst, however, in this case, the 5-(alkoxymethyl)furfural is formed through a dehydration/esterification mechanism, reaching product yields above $70 \%{ }^{83}$ Although, the 5-(alkoxymethyl)furfural are not platform molecules as flexible as HMF, it has potential to be used as biodiesel, as well as other alkoxyfurans. ${ }^{83,84}$

Another interesting approach for a sustainable use of solvents in the biomass conversion is turning the reactions products into the own reaction solvent, eliminating, therefore, separation steps. A clever example was the production of GVL from cellulose (using GVL as a solvent), as shown in Figure $7 .{ }^{29} \mathrm{In}$ this case, cellulose was directly converted into LA in a biphasic solvent system (as described above) using GVL as the organic extracting layer. Then, LA was converted by hydrogenation to GVL with a $\mathrm{PtSn} / \mathrm{C}$ catalyst (Figure 7).

Indeed, GVL has been proposed as an important solvent for biomass conversion, mainly during sugar conversion steps. Many examples (Table 1) have shown a significant improvement in the product yield when using GVL (with water as co-solvent) instead of pure water as solvent for: (i) the conversion of raw biomass into soluble sugars; ${ }^{85-87}$ (ii) glucose or fructose to HMF; ; 7,74 (iii) cellulose to LA ${ }^{26}$ and (iv) hemicellulose or xylose to furfural. ${ }^{88}$

The ideal GVL/water ratio varies from reaction to reaction (Table 1); furthermore, pure GVL also leads to lower product yields compared to GVL/water mixture. Other aprotic solvents, such as DMSO, THF and dioxane have shown similar results. ${ }^{74,86,89,90}$ Molecular dynamic investigation of fructose conversion into $\mathrm{HMF}$ in a DMSO/ $\mathrm{H}_{2} \mathrm{O}$ solvent system has shown that DMSO competes with water

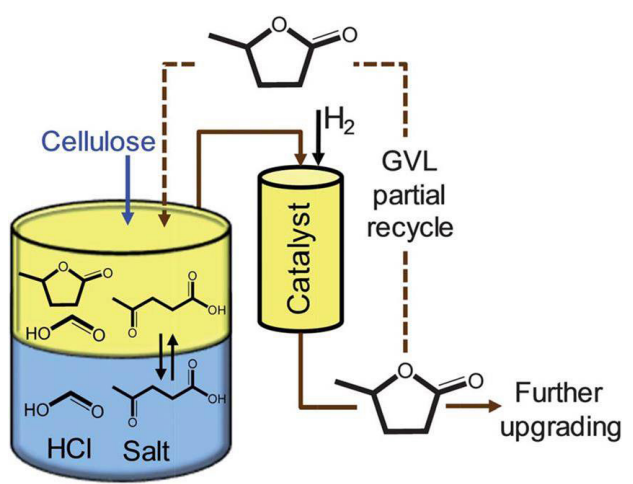

Figure 7. Integrated conversion of cellulose to GVL using GVL as a solvent (from reference 29; copyright 2012 by The Royal Society of Chemistry. Reproduced with permission).

in the solvation of both reactant and product. ${ }^{78}$ DMSO acts as a hydrogen acceptor, interacting more effectively than water with hydrogen from hydroxyl groups in both fructose and HMF, while water can interact with the oxygen atom of the same hydroxyl groups. Therefore, the product yields tend to be higher in the presence of the aprotic solvent DMSO because: (i) its interaction with the fructose hydroxyl groups prevents deprotonation, and consequently, polymerization to undesirable products and (ii) its interaction with the HMF hydroxyl groups prevents rehydration, which could lead to the undesirable humins. ${ }^{78}$

Another important effect of DMSO is increasing the fructose dehydration reaction rate. It has been found that the slowest steps of the reaction involve intramolecular hydride transfer, requiring a reorganization of the polar solvent environment and the solvation of asymmetrically distributed electronic charges. Therefore, the presence of a solvent with a dielectric constant lower than water, such as DMSO, can accelerate the reaction. ${ }^{11}$

Using the conversation of xylose to furfural as model reaction, a kinetic model was built considering the furfural

Table 1. Reaction yields of selected biorefinery-related reaction using water or GVL as solvent

\begin{tabular}{|c|c|c|c|c|}
\hline Reaction & $\begin{array}{c}\text { Solvent, weight ratio GVL/ } \\
\text { water }\end{array}$ & Catalyst & Yield $^{\mathrm{a}} / \%$ & Reference \\
\hline \multirow[t]{2}{*}{ Biomass to soluble sugars } & $0 / 1$ & \multirow[t]{2}{*}{$\mathrm{H}_{2} \mathrm{SO}_{4}$} & ca. $68 \mathrm{Xyl}$, ca. $45 \mathrm{Glu}^{\mathrm{b}}$ & \multirow[t]{2}{*}{87} \\
\hline & $8 / 2$ & & ca. $88 \mathrm{Xyl}$, ca. $80 \mathrm{Glu}^{\mathrm{b}}$ & \\
\hline \multirow[t]{2}{*}{ Xylose to furfural } & $0 / 1$ & \multirow[t]{2}{*}{ Amberlyst 70 (sulfonated resin) } & ca. 48 & \multirow[t]{2}{*}{88} \\
\hline & $8 / 2$ & & ca. 80 & \\
\hline \multirow[t]{2}{*}{ Cellulose to LA } & $0 / 1$ & \multirow[t]{2}{*}{$\mathrm{H}_{2} \mathrm{SO}_{4}$} & 36 & \multirow[t]{2}{*}{26} \\
\hline & $9 / 1$ & & 59 & \\
\hline \multirow[t]{2}{*}{ Furfuryl alcohol to LA } & $0 / 1$ & \multirow[t]{2}{*}{$\mathrm{H}_{2} \mathrm{SO}_{4}$} & ca. 10 & \multirow[t]{2}{*}{90} \\
\hline & $19(\mathrm{THF}) / 1^{\mathrm{c}}$ & & ca. 55 & \\
\hline
\end{tabular}

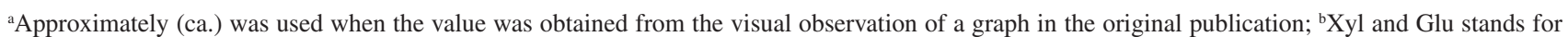
xylose and glucose, respectively. The value presents were obtained by summing the yield for soluble mono- and polysaccharides; ${ }^{c}$ results using THF as solvent instead of GVL; GVL: $\gamma$-valerolactone; LA: levulinic acid; THF: tetrahydrofuran. 
formation (rate constant $\mathrm{k} 1$ ) and the degradation pathways involving the reactant and products ( $\mathrm{k} 2, \mathrm{k} 3$, and $\mathrm{k} 4)$, as shown in Figure 8A.$^{86}$ The challenge in this type of reaction is that the acid catalyzes not only the reaction of interest but also the degradation and polymerization of reactants and products. It has been found that using the mixture $\mathrm{GVL} /$ water in a weight ratio $9 / 1$, the rate constant for furfural formation (k1) is approximately 31 times higher than in pure water. Regarding the rate constant of degradation reactions, only $\mathrm{k} 4$ increases proportionally with $\mathrm{k} 1$ when GVL/water 9/1 system is used instead of pure water, while $\mathrm{k} 2$ decreases slightly and $\mathrm{k} 3$ increases by only 8 times. ${ }^{86}$ Therefore, in the GVL solvent system, the reaction rate for product formation increases more than the reaction rates for formation of undesirable byproducts, which explains the higher yields. Furthermore, calculation of the Gibbs free energy of the Brønsted acid catalyzed reaction in water or aprotic organic solvent, showed a higher stabilization of the proton solvated by water (more negative $\Delta \mathrm{G}$ ), which implies in a less reactive proton if compared to the proton solvated by aprotic solvents (Figure $8 \mathrm{~B}$ ) ${ }^{86}$ leading to lower reaction rate in pure water over GVL.

The solvent system GVL/water has also presented superior results than pure water in the depolymerization of biomass into sugars. Using sulfuric acid as catalyst, biomass can be selectively deconstructed to soluble mono and polysaccharides, without further dehydration to HMF and furfural. ${ }^{87}$ The selective formation of soluble saccharides is important, for example, for the production of second-generation bioethanol. Further studies have shown that while the apparent activation energies for cellulose depolymerization and the glucose or xylose conversion are similar in water, in GVL the activation energy for the depolymerization is significantly lower. ${ }^{92}$ Therefore, when GVL is used as a solvent, it is possible to obtain selectively soluble saccharides. Other studies also indicate that entropy might have a determinant role in explaining cellulose dissolution in water. In water, entropy becomes positive as temperature increases, and in ionic liquids, for instance, the entropy is positive even at room temperature..$^{93}$

For liquid phase reactions, the system using biomassderived aprotic solvents seems to be the best alternative for biomass conversion, however, there is a lot to be understood in the role of the solvent, as well as, eventually design reaction systems to minimize the need of the organic solvents. An integrated knowledge concerning the solvent system, its action mechanism, and the reaction mechanisms over the catalyst surface will be fundamental for designing improved reaction systems. Therefore, further studies must be carried seeking a better understand the solvent effect and correlating it with its intrinsic properties.

\section{Catalysts: Towards Heterogeneous Ca- talysis, Bifunctional Catalysts and Processes Integration}

Designing a sustainable and cost-effective biorefinery is still a great challenge to be overcome. ${ }^{94-96}$ The cost of the biomass-derived product is affected by several factors, including crops (efficiency, management and transportation), biomass pre-treatment (drying, grounding, depolymerizing), chemical process (productivity, product
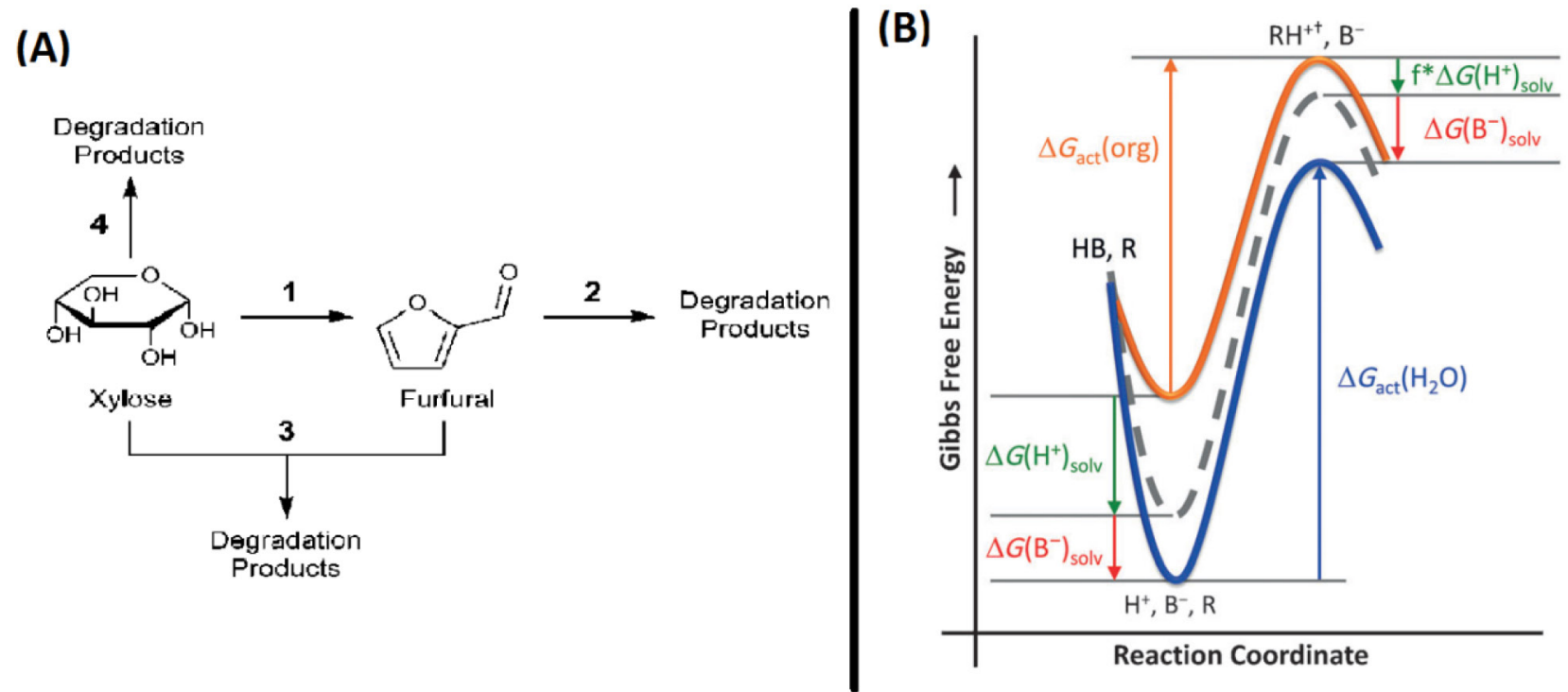

Figure 8. (A) Proposed reaction network for the catalyzed xylose dehydration in furfural and (B) Gibbs free energy of the Brønsted acid catalyzed reaction in water or aprotic organic solvent (adapted from reference 86; copyright 2014 by John Wiley \& Sons, Inc. Reproduced with permission). 
separation and purification), and market demand. From the chemical point of view, there are important features to be addressed aiming a cost-effective chemical process: ${ }^{97}$

(i) Replacement of corrosive substances (e.g., mineral acids), improvement of biomass hydrolysis efficiency and development of processes compatible with different biomass feedstocks;

(ii) Enhance the product yields;

(iii) Design of energy efficient processes that require minimum product separation;

(iv) Processes integration, development of one-pot processes, and maximization of the number of reaction steps that can be performed in a single reactor and/or integration between chemical and biological catalysis.

Therefore, some aforementioned challenges can be overcome by the development of adequate catalytic systems. For example:

(i) By replacing the homogeneous mineral acids catalysts by heterogeneous ones without compromising the product yield;

(ii) Understanding the reaction pathways, and hence, designing catalysts with higher performance;

(iii) Designing catalytic systems that allow performing multiple reaction steps in one-pot regime, or with integrated reactors, diminishing the need of separation steps and reducing the process cost;

(iv) Similarly, designing bi- or multifunctional catalysts that can catalyze multiple reactions minimizing the number of separation procedures.

Hence, the catalyst system has a crucial role in diminishing the cost of chemical processes. Therefore, a rational design of catalysts will be essential for implementation and success of biorefineries. In general, the use of zeolites is particularly interesting on replacing homogeneous mineral acids. Along with metal oxides, zeolites are the most important solid catalysts in chemical industry (together they account for $70 \%$ of the industrial catalysts) due to their economical prices, high activity and stability. ${ }^{95}$ One of the main challenges in using already existing heterogeneous oxide-based catalysts is that they were initially designed to be employed for processing fossil fuel derived compounds, ${ }^{98,99}$ which involves reaction conditions substantially different from biomass conversion. In the conversion of biomass, frequently, high temperature are employed and water is present (the feedstock is inherently wet, and water is a common by-product and solvent as well). Under these conditions, the dissociation of water is favored, generating an environment prone to react with the surface of oxide-based catalysts promoting hydrolysis and re-condensation of surface species, which can lead to phase transformation, collapse of structure and pores, and surface area reduction. ${ }^{100}$
Silica and aluminosilicates are especially unstable under hydrothermal conditions, due to the hydrolysis of the $\mathrm{Si}-\mathrm{O}-\mathrm{Si}_{\text {(Surf) }}$ and $\mathrm{Si}-\mathrm{O}-\mathrm{Al}_{\text {(Suf) }}$ bonds, forming soluble silicates and collapsing the structure. ${ }^{101,102}$ For instance, the collapse of the mesoporous silica SBA-15 structure takes place in few hours after hydrothermal treatment at $200{ }^{\circ} \mathrm{C} .{ }^{36}$ In general, zeolites, crystalline aluminosilicates, are significantly more stable then amorphous silica and aluminosilicates due to less functionalized structure and more hydrophobic structure. In general, dense-structured zeolites, such as ZSM-5 and mordenite display better hydrothermal stability in hot water than the open-structured ones (types Y: BEA and FAU). ${ }^{101,102}$ Furthermore, zeolites with lower particle sizes (i.e., more exposed surface) and higher aluminum loading (i.e., more hydrophilic) tend to present lower hydrothermal stability. ${ }^{101-104}$ In general, the stability of silicas, aluminosilicates and zeolites can be improved by modification of the surface with hydrophobic organic groups ${ }^{103}$ or by stabilizing with a cation that promotes strong interaction with the surface hydroxyl groups. ${ }^{105,106}$ As it regards metal oxides, hydrothermal conditions can lead to decrease of catalytic activity due to transformation of the phase to one with lower surface area and collapse of the porous structure. ${ }^{35,100,107}$ For instance, the deposition of carbon layer over the alumina surface has shown to improve significantly its hydrothermal stability. ${ }^{107}$ In the initial stage of studying biomass conversion, it is natural to use the well-established catalysts, since stability will not always be an issue. However, whenever the catalyst is unstable, new catalysts, with improved properties must be designed.

For xylose conversion in monophasic solvent system (GVL containing 20 wt.\% of water), a benchmark study showed that zeolites and sulfonic acid based solid catalysts led to furfural yields comparable or higher than the homogeneous sulfuric acid (except for the ZSM-5 Zeolite, probably due to its small pores). Contrarily, pure Lewis acid solid catalysts and metal oxides presented poor selectivity to the desired product (Figure 9). ${ }^{88}$

Further studies comparing zeolites and sulfuric acid for xylose conversion have revealed that the acid aluminosilicate Beta Zeolite (H-Beta) presents significantly strong Lewis acids that are able to modify the mechanism of the reaction: xylose is first isomerized to xylulose and lyxose, which are then dehydrated to furfural (Figure 10). ${ }^{108}$ Although the isomerization/dehydration does not lead to a higher furfural yield, the turnover frequency (TOF) increases by 2 and 5.5 folds when compared to Mordenite and sulfuric acid, respectively. Similar behavior is also observed for arabinose, another pentose commonly present in hemicellulose, however, in this case, the isomerization/ 


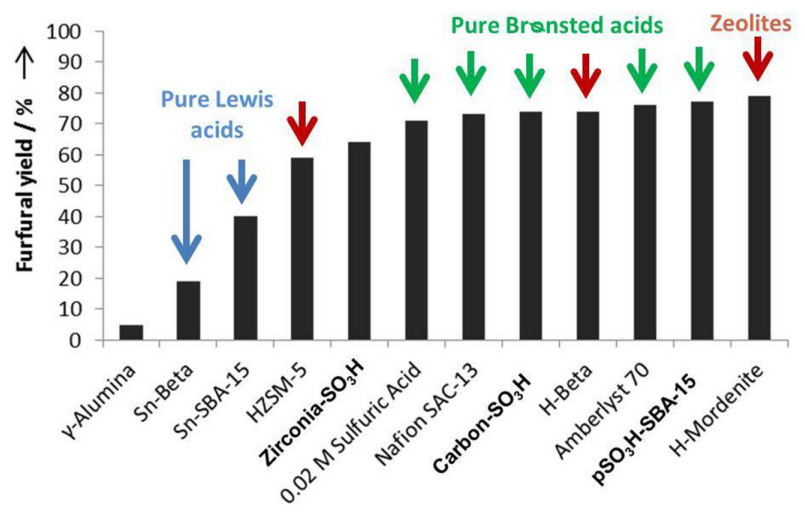

Figure 9. Furfural yield from xylose dehydration catalyzed by several acid catalysts (adapted from reference 88, copyright 2013 by John Wiley $\&$ Sons, Inc. Reproduced with permission).

dehydration reaction pathway catalyzed by $\mathrm{H}$-Beta leads to both increase in TOF and in the furfural yield. ${ }^{108}$ The H-Beta catalyst showed deactivation due to carbon deposition, and the catalyst activity was fully restored upon calcination. Hence, H-Beta structure showed important resistance under the reaction conditions. ${ }^{108}$ Other studies using a combination of a tinsilicate Zeolite (Sn-Beta) as Lewis acid and Amberlyst-15 (a sulfonated cross-linked polystyrene resin) as Brønsted acid have confirmed an isomerization/ dehydration pathway. However, under these conditions, lower furfural yields (> 20\%) were obtained. ${ }^{109}$

Although Sn-Beta was not particularly efficient for xylose conversion, this catalyst has gained attention in the biomass conversion field, once it is one of the few solid water resistant strong Lewis acid catalysts. An interesting application for this catalyst has been in Diels-Alder reactions between biomass-derived furans and ethylene, which yield several functionalized aromatics. ${ }^{23,74}$ The advantage of Sn-Beta over other catalysts is its ability to promote Diels-Alder reaction even in functionalized furans at moderated pressure and temperature, leading to functionalized aromatics with application as monomers for polymers and industrial intermediates. ${ }^{15,16,110}$

Even though zeolites are excellent solid acids, they are not always the most appropriate catalysts. ${ }^{111-114}$ For example, for the conversion of glucose or fructose to 5-hydroxymethylfurfural ${ }^{12,114}$ and glucose or cellulose to LA, ${ }^{113,115}$ catalysts containing heterogeneized sulfonic acid groups were significantly more selective than zeolites. Although sulfonic acid based catalysts are very selective for production of HMF and LA from monosaccharides, they were found to have poor stability, mainly in the presence of water. For instance, the mesoporous silica SBA-15 containing propylsulfonic acid groups ( $\left.\mathrm{pSO}_{3} \mathrm{H}-\mathrm{SBA}-15\right)$ showed pronounced deactivation for dehydration of fructose using THF/water (weight ratio of 4/1) as solvent. ${ }^{116}$ It has been shown that deactivation was mainly due to the hydrolysis of 3-(trihydroxysilyl)1-propanesulfonic acid groups. SBA-15-type periodic mesoporous organosilicas containing sulfonic acid groups have shown higher stability than the silica SBA-15,
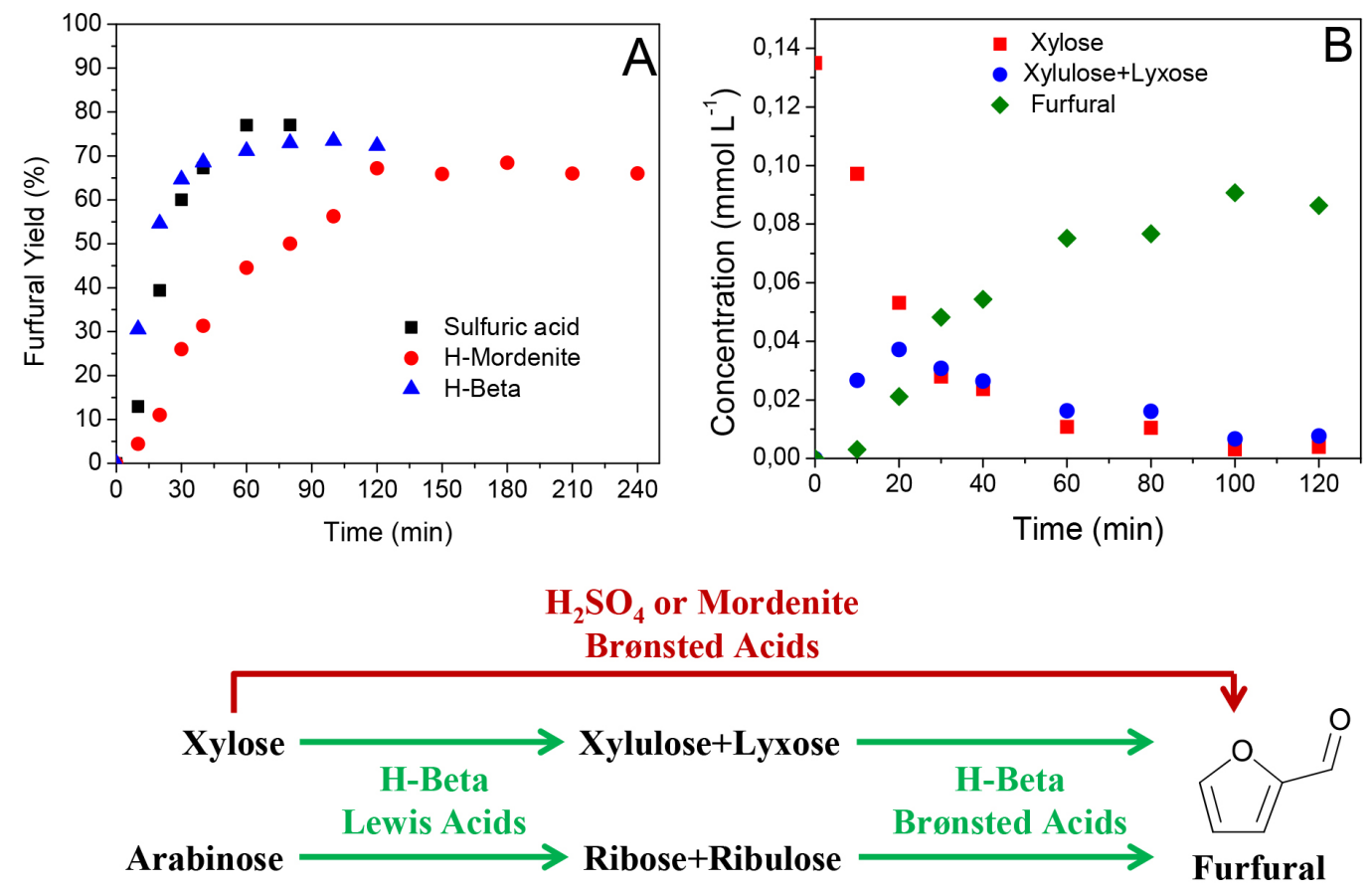

Figure 10. (A) Comparison of the activity of zeolites and sulfuric acid for xylose to furfural reactions; (B) kinetics study of the xylose to furfural reaction catalyzed by H-Beta; and (reaction scheme) xylose or arabinose to furfural reaction network catalyzed by pure Brønsted acid catalyst and bifunctional H-Beta (adapted from reference 108; copyright 2013 by Springer. Adapted with permission). 
however; still significantly lower than the commercial non-siliceous catalysts. ${ }^{116}$

Regarding biomass conversion, the catalyst hydrothermal stability is indeed a major concern, since biomass is inherently wet and water is commonly used as solvent or cosolvent. Commercial sulfonated cross-linked polystyrene resins (such the Amberlyst ion exchange resins) appear as important alternatives, since they are selective on reactions of dehydration of sugars and water resistant; however, they are not flexible to structure and surface modifications and limited regarding high temperature applications. Recently, it has been proposed the preparation of mesoporous carbons modified with phenylsulfonic acid or naphthalenesulfonic acid functional groups ${ }^{89}$ In this case, the functional groups are connected to the support through a stable $\mathrm{C}-\mathrm{C}$ bond, and therefore the stability is up to 60 times higher than for the $\mathrm{pSO}_{3} \mathrm{H}-\mathrm{SBA}-15$ and up to 4 times higher than the commercial sulfonated resin Nafion SAC-13. ${ }^{89}$

Another approach for preparation of stable catalysts employed the coverage of $\mathrm{pSO}_{3} \mathrm{H}-\mathrm{SBA}-15$ siliceous surface with polyvinylpyrrolidone (PVP), as shown in Figure 11; in this case, it was observed an improvement of 2.5 times in the catalysts stability. However, the most interesting feature of the PVP- $\mathrm{pSO}_{3} \mathrm{H}-\mathrm{SBA}-15$ was actually related to the catalyst performance: at similar conversion, the addition of PVP in the catalyst pores led to an increase in the HMF selectivity from 68 to $87 \% .{ }^{117} \mathrm{PVP}$ was shown to modify the chemical environment inside the pores and promote a shift in the equilibrium towards the formation of fructofuranose form at the expenses of the fructopyranose, the most abundant isomer. The conversion of fructose into HMF is more selective when taking place from the furanose form, therefore, enriching the core of the pores with this isomer improves the catalyst performance and the HMF yield. ${ }^{117}$

The importance of solvent on biomass conversion was herein already mentioned, but the PVP-pSO3H-SBA-15 shows that the chemical environment inside the catalyst pores, can be as important as the solvent and must not be neglected. Similarly, combining the understanding of solvent system and surface chemistry has helped to solve old problems in biomass conversion (i.e., in the conversion of furfuryl alcohol in LA). As mentioned before, this reaction is particularly important since it integrates the hemicellulose reaction roadmap with the well-developed cellulose one.

Furfuryl alcohol is extremely prone to polymerization in the presence of heat or acid catalyst. To minimize polymerization problems, the conversion of furfuryl alcohol is usually carried out at low feed concentration ${ }^{118,119}$ or in the presence of alcohol to obtain the levulinate esters, ${ }^{118}$ which must then be hydrolyzed to LA. Using a mixture of THF/water as solvent, it has been observed for various catalysts (e.g., Mordenite, sulfuric acid, Amberlyst-70) that the higher water weight fraction in the solvent or the higher the reactant concentration, the lower LA selectivity. ${ }^{90}$ Conversely, the acid catalyst ZSM-5 Zeolite showed extremely low sensitivity to water or reactant concentration, and similar LA selectivity were obtained at various THF/water ratio (19/1 to 2/1) or furfuryl alcohol concentrations $\left(0.2\right.$ to $\left.1 \mathrm{~mol} \mathrm{~L}^{-1}\right) \cdot{ }^{90}$ It was proposed that the hydrophobic surface of ZSM-5 would lead to a different degree of permeation of THF and water. Therefore, the environment inside the pore would be always richer in THF than water, no matter the water concentration in the "external" solvent. ${ }^{90}$ ZSM-5 activity showed to decrease after each cycle of reutilization, however, the initial activity could be recovered after calcination. This indicates, that the zeolite structure was stable under the reaction conditions, and the deactivation was mainly due to coking. ${ }^{90}$

Undoubtedly, the understanding of the catalysts and reaction pathways involved on the conversion of biomassderived monosaccharides has been fundamental for
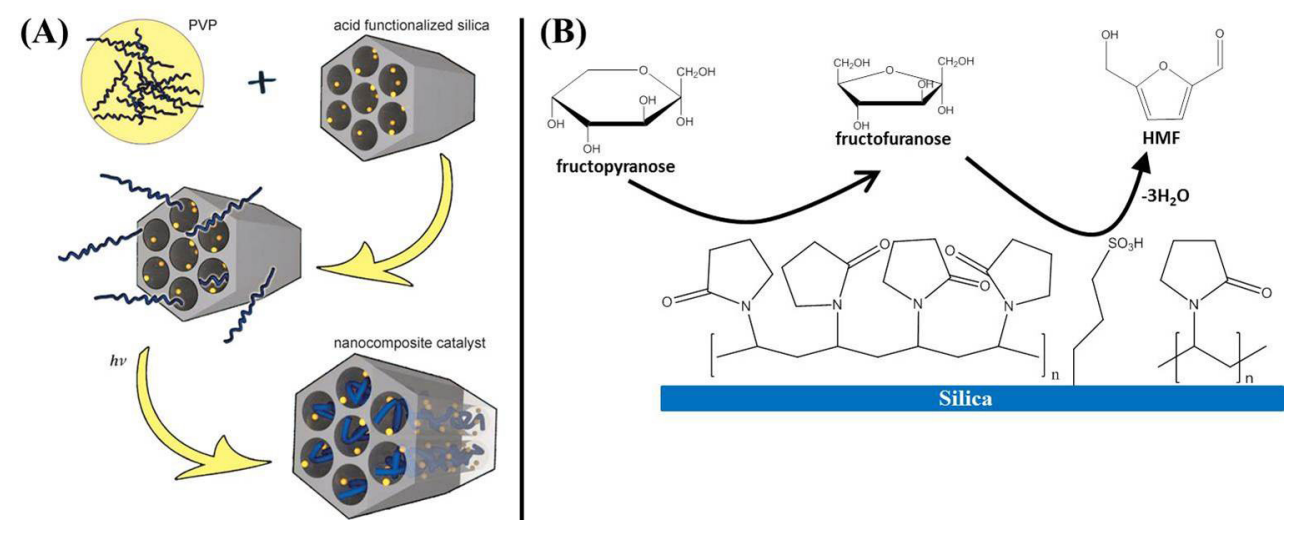

Figure 11. (A) Scheme of introduction of $\mathrm{PVP}$ in $\mathrm{pSO}_{3} \mathrm{H}-\mathrm{SBA}-15$; (B) reaction pathway inside the pores of the $\mathrm{PVP}-\mathrm{pSO}_{3} \mathrm{H}-\mathrm{SBA}_{-15}$ (Figure A reprinted from reference 117; copyright 2013 by John Wiley \& Sons, Inc. Reproduced with permission). 
establishing the first pillars of the biorefinery. Seeking the cost-effectiveness of the processes, a major concern from the next years might be towards the integration of processes, carrying on reactions on one-pot regime, and the development of bi- or multifunctional catalysts. ${ }^{120}$

One important example of the requirement of having two catalytic functionalities (although not necessarily involving a bifunctional catalyst) is the conversion of glucose in HMF. In several examples abovementioned, we discussed the synthesis of HMF from fructose. Fructose is not obtained directly from cellulose; it is commercially produced from glucose isomerization, being consequently more expensive. However, a straight conversion of glucose to HMF catalyzed only for a Brønsted acid leads to low selectivity, probably, because in solution the contribution of the furanose isomer is around just 1\% (against ca. 20\% in fructose). And as mentioned before, HMF is preferentially formed from the dehydration of the furanose form of the hexose.

Using a biphasic solvent system, it was proposed that a combination of Sn-Beta (as Lewis acid) and hydrochloric acid (as Brønsted acid) promotes the one-pot conversion of glucose to HMF with high yields. ${ }^{121,122}$ As mentioned before, the biphasic systems relied on salts to guarantee the solvents separation. The effect of salts cannot be neglected, since it can affect the solid catalyst surface properties as well as the reaction mechanism. For instance, alkaline metal cations were shown to disrupt the water structure in the solvation sphere of pentose sugars, leading to a weakening of $\mathrm{C}-\mathrm{O}$ bonds, while halide anions can interact with the positive end of hydroxyl groups on the monosaccharide, affecting the reaction network, as well as the catalyst performance. ${ }^{123}$ For instance, chlorination of alumina at high temperatures, leads to a complete elimination of Brønsted acid aluminol groups, and a significant increase in the Lewis acid loading and strength. ${ }^{124-127}$ Furthermore, the presence of chlorine in solution can difficult the integration of the sugar dehydration process, with the next step, which usually involves a metal catalyzed reduction or oxidation. Chloride ions are known to promote deactivation of metal nanoparticle based catalyst due to sintering or poisoning. ${ }^{128,129}$

In a similar biphasic solvent system, a combination of homogeneous Lewis acids (Al, Sn, V, Ga, In, Yb, Dy and $\mathrm{La}$ chlorides) and $\mathrm{HCl}$ (as Brønsted acid) led to up to $62 \%$ yield for HMF directly from fructose, ${ }^{82,130}$ which can be further improved using n-butanol as solvent and small amounts of $\mathrm{LiCl} .{ }^{131}$ In both cases, it has been shown that the Lewis acid is responsible for in situ isomerization of fructose, which is then dehydrated by $\mathrm{HCl}$ in HMF. Subsequently, a system using only heterogeneous catalysts, composed by a combination of Sn-Beta and Amberlyst-70 (Lewis and Brønsted acids, respectively), in a monophasic solvent system (such as GVL and THF with $10 \%$ of water) was able to achieve $63 \%$ yield to HMF, i.e., superior result compared to the homogeneous systems. ${ }^{74}$ Furthermore, the use of simple solvent system and heterogeneous catalysts allowed an easy integration of the HMF production with upgrading reactions to 2,5-furandicarboxylic acid (FDCA) and 2,5-dimethylfuran (DMF), with yields of up to 50 and $27 \%$, respectively (respect to the glucose) (Figure 12).

It is worth mentioning that $\mathrm{Ti}-, \mathrm{Zr}$ - and $\mathrm{Sn}$-Beta have risen as powerful and flexible water-resistant solid Lewis acid catalysts. For monosaccharide isomerization, Sn-Beta has

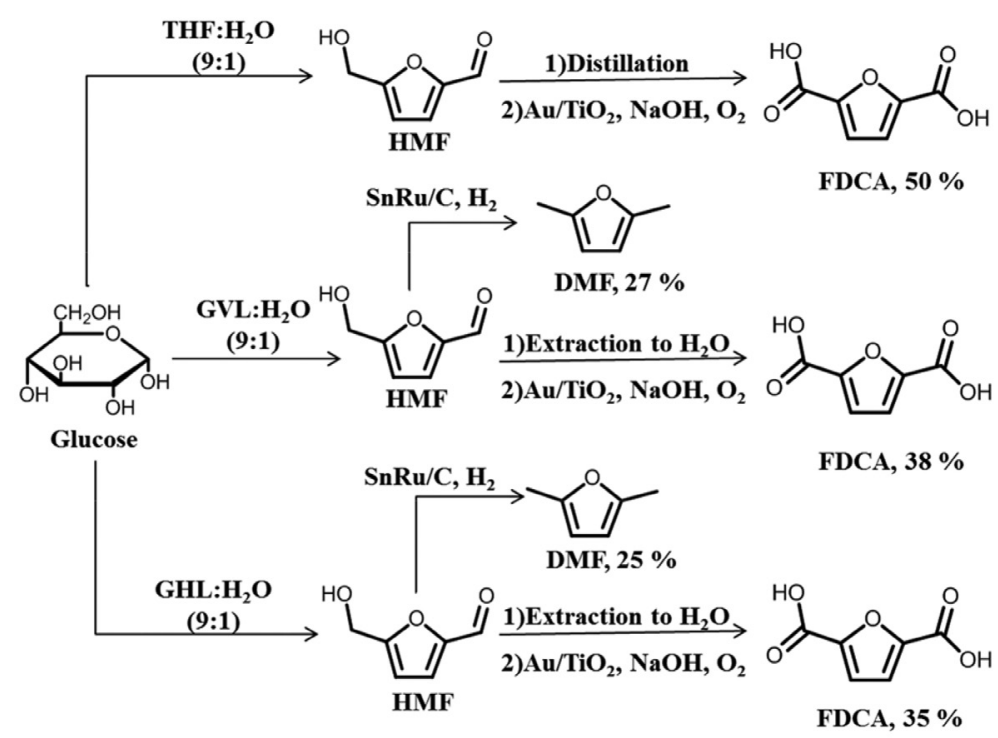

Figure 12. Process integration and overall yields for DMF and FDCA production from glucose (adapted from reference 74; adapted with permission from The Royal Society of Chemistry). 
displayed the best results. ${ }^{122,132,133}$ In this catalyst, Sn occupies tetrahedral positions in the crystalline silica framework, and two main $\mathrm{Sn}$ species are possible: $(i)$ the close sites, $(\mathrm{SiO})_{4} \mathrm{Sn}$ and $(\mathrm{ii})$ the open sites, $(\mathrm{SiO})_{3} \mathrm{Sn}(\mathrm{OH})$. The open sites are generated by the hydrolysis of one $\mathrm{Sn}-\mathrm{O}-\mathrm{Si}$ bond of the closed sites, and therefore, vicinal to the open sites, it is always expected a silanol $(\mathrm{Si}-\mathrm{OH})$ group. ${ }^{133-136}$ For the glucose isomerization, it has been observed that the Sn open site acts as a Lewis acid, which activates the acyclic form of glucose by polarizing the carbonyl group, while the silanol binds to the hydroxyl group on the $\mathrm{C} 2$ carbon. ${ }^{132,137,138}$ When only close sites are present, Sn-Beta is not active for the isomerization, promoting instead the glucose epimerization to mannose. ${ }^{139-141}$

A less environmentally friendly, but not less interesting example, uses a mixture of $N, N$-dimethylacetamide (DMA) and $\mathrm{LiCl}$ as solvent and the ionic liquid 1-ethyl3-methylimidazolium chloride ([EMIM]Cl) as an additive in order to produce HMF. ${ }^{81} \mathrm{HMF}$ was obtained from fructose, glucose, cellulose and raw biomass with high yields using sulfuric acid as Brønsted acid and $\mathrm{CrCl}_{3}$ as Lewis acid (Figure 13). This process also allowed the process integration with the HMF conversion to DMF, however, with low yields. ${ }^{81}$ Other catalytic systems using ionic liquids as solvents, a heteropolyacid as Brønsted acid and $\mathrm{Pt} / \mathrm{C}$ as redox catalyst, proposed the integrated production of DMF from glucose, reaching an overall yield of $15 \% .^{142}$ Obtaining a high DMF yield by HMF hydrogenation has shown to be challenging due to the reaction sensitive to the solvent and catalytic system. Recently, it has been found that the HMF hydrogenation by $\mathrm{H}$-transfer using isopropanol and a physical mixture of $\mathrm{Ru}$ and $\mathrm{RuO}_{2}$ as catalyst can lead to up to $72 \%$ yield to DMF. ${ }^{143}$

The combination of acid and redox catalysts can also allow a different reaction network. Depending on the nature of the acid catalyst and the reaction conditions, cellulose can be selectively hydrolyzed for production of saccharides, which can be then hydrogenated to hexitol (such as sorbitol, mannitol and sorbitan). ${ }^{14-148}$ For instance, Ru/H-USY with traces of $\mathrm{HCl}$ can lead to hexitol yields of up to $80 \% .{ }^{145}$

In the hemicellulose roadmap, a clever example reports the integrated production of GVL from furfural by Lewis acid catalyzed hydrogen transfer (Zr-Beta) and Brønsted acid catalyzed hydrolysis (Al-MFI aluminosilicate) (Figure 14). ${ }^{149}$ The nature of the H-transfer catalyst is highly important for this reaction network, for instance, if $\mathrm{Ru} / \mathrm{RuO}_{2}$ is used, furfural is preferentially hydrogenated to 2-methylfuran instead of furfuryl ether. ${ }^{150}$

Interestingly, the examples of one-pot conversion of glucose to HMF, or furfural to GVL use combinations of catalysts with different functionalities instead of bifunctional catalysts. On the other hand, xylose and arabinose conversion to furfural was performed with the bifunctional H-Beta and the conversion of fructose to $\mathrm{HMF}$ with the bifunctional PVP-SO $\mathrm{H}-\mathrm{SBA}-15$. So, at this point, it is important to think over which would be the better option for these conversions: bifunctional catalysts or a combination of catalysts with different

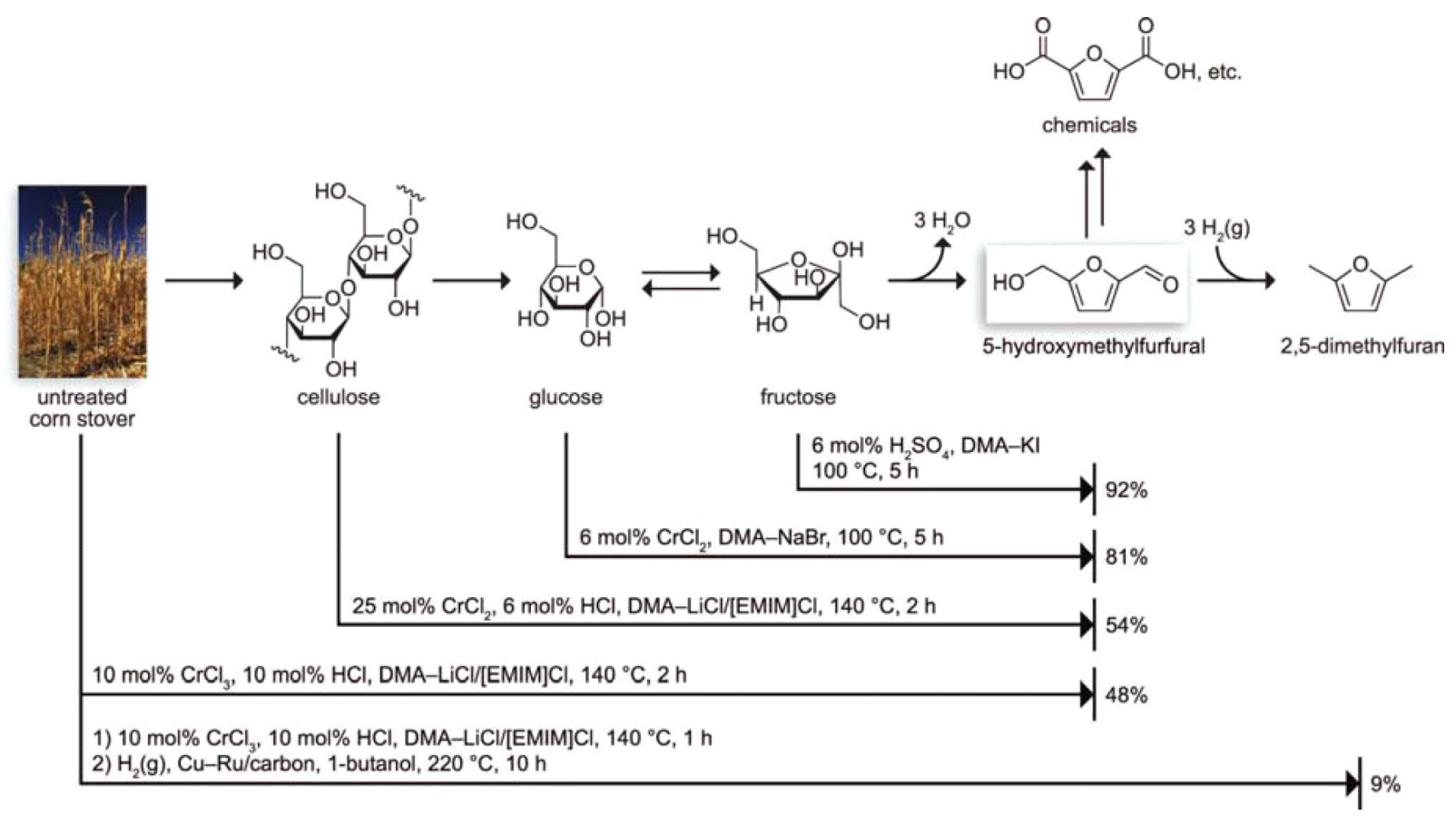

Figure 13. HMF synthesis from corn stover, cellulose, glucose and fructose using DMA-LiCl/[EMIM]Cl solvent system (reproduced from reference 81; copyright 2009 American Chemical Society. Reproduced with permission). 


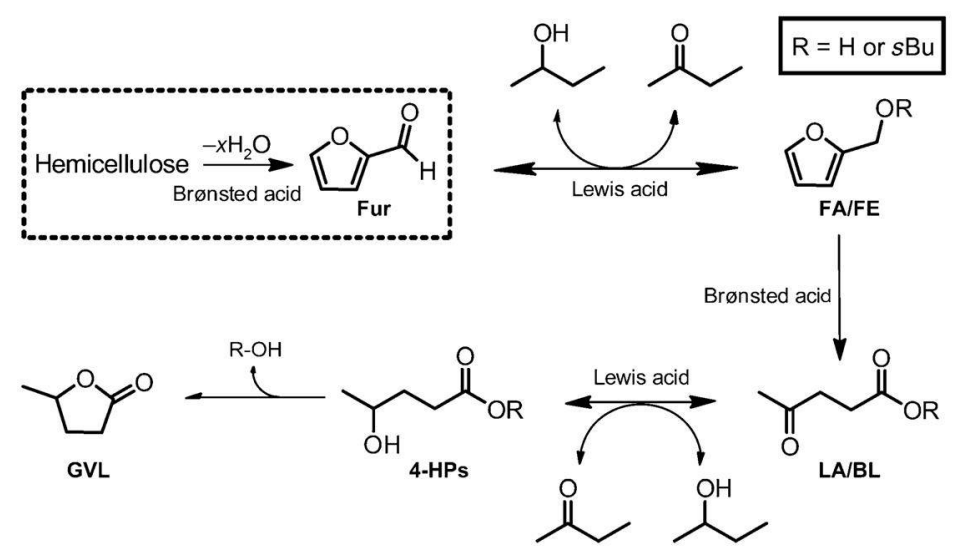

Figure 14. Integrated production of GVL from furfural (reprinted from reference 149; copyright 2013 by John Wiley \& Sons, Inc.; Reprinted with permission).

functionalities. Trying to answer this question, we can go back to the glucose to HMF example: the HMF yield using the combination of Sn-Beta and Amberlyst-70 was significantly higher than using bifunctional catalysts such as a sulfonic acid functionalized metal-organic framework $\mathrm{MIL}-101(\mathrm{Cr})-\mathrm{SO}_{3} \mathrm{H},{ }^{151} \mathrm{SO}_{4} / \mathrm{ZrO}_{2},{ }^{152}$ or $\mathrm{SO}_{4}{ }^{2-} / \mathrm{ZrO}_{2}-\mathrm{Al}_{2} \mathrm{O}_{3}{ }^{153}$ The bifunctional concept implies that once fructose is formed from glucose, it is readily converted to HMF in a neighbor site, which avoids side reactions, due to fructose interaction with other byproducts or due to its decomposition. Conceptually, the bifunctional catalyst would be ideal; however it does not support most of the literature results: maybe we just have not been able to make the right bifunctional catalyst yet. Indeed, other examples in which bifunctional catalysts are better than combination of catalysts have been already mentioned. For instance, the furfural yields from xylose or arabinose is higher using the bifunctional H-Beta than the combination of Sn-Beta and Amberlyst. ${ }^{23,74,108} \mathrm{H}$-Beta is not an efficient catalyst for HMF production from glucose, even though it is bifunctional. ${ }^{154}$ Similarly, HMF yield is higher using the bifunctional PVP-SO ${ }_{3} \mathrm{H}-\mathrm{SBA}-15$ than a combination of PVP in solution and $\mathrm{SO}_{3} \mathrm{H}-\mathrm{SBA}-15 .{ }^{117}$

Bifunctional catalysts containing redox and acid functionalities (usually metal nanoparticles supported in metal oxides) also have important application in the conversion of biomass-derived saccharides. For instance, $\mathrm{Pd} / \mathrm{Nb}_{2} \mathrm{O}_{5}$ catalyst was used for the direct conversion of GVL into pentanoic acid, a precursor for the bio-based production of gasoline, diesel and jet fuels. ${ }^{35}$ In this bifunctional catalyst, the acidic niobium oxide catalyzes the ring-opening of GVL to pentenoic acid, followed by its hydrogenation to pentanoic acid by Pd nanoparticles. Although a good catalytic performance was observed, the catalyst showed quick deactivation due to the niobium oxide phase transformation from the high surface area amorphous to the low surface area crystalline, along with sintering of the metal nanoparticles. ${ }^{35}$ Indeed, transformations on the catalyst inside the reactor are major concerns on biomass conversion, mainly because they can be facilitated by the presence of water. The stability of the catalyst can be improved by coating a high surface area mesoporous silica scaffold with niobium atomic layers (SBA-15-ALD-19), as shown in Figure 15A. ${ }^{36}$ The interaction between silicon and niobium oxides prevents the phase transformation and the porosity guarantees a good dispersion of the Pd nanoparticles. While $\mathrm{Pd} / \mathrm{Nb}_{2} \mathrm{O}_{5}$ presented two deactivation stages with first order deactivation constants of 0.0597 and $0.0203 \mathrm{~h}^{-1}$, for the Pd/SBA-15-ALD-19 respectively, the deactivation rate constant decreases to $0.0061 \mathrm{~h}^{-1}$ (Figure 15B) ${ }^{36}$

Regarding the conversion of biomass, along with the understanding of the solvent system, it is extremely important to design optimal catalysts for improving the desired product yields. As discussed in this section, using the right functionality is not enough to guarantee a good performance: for instance, an acid catalyzed reaction will not reach good selectivity with any acid. Therefore, it is important to have a prior understanding of the reaction mechanism and the chemical properties of the reactants, products and intermediates before designing the catalyst. Once achieved this understanding, the challenge becomes designing integrated processes and bifunctional catalysts and, hence, seek for processes with lower cost. Catalyst stability is another major issue on biomass conversion, mainly because the presence of water is almost inevitable.

\section{Seeking the Sustainability}

Very often sustainability is confused with renewable or with green chemistry. These concepts can be correlated, but are not synonyms. A green process may not be sustainable, and a sustainable process may not follow all the green chemistry requirements. Likewise, a sustainable process may or may not use a renewable feedstock, since it depends 


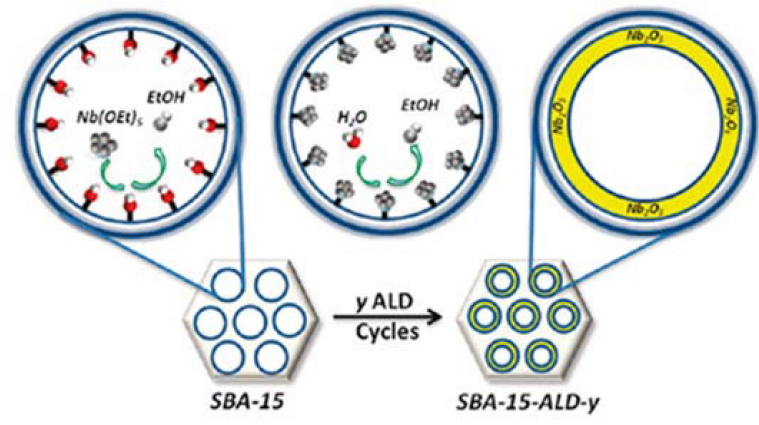

(A)

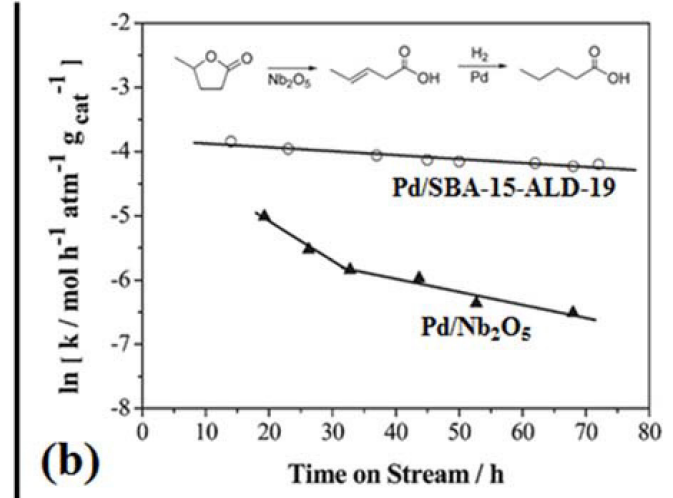

Figure 15. (A) Coating of the mesoporous silica with niobium oxide atom layer and (b) first order deactivation studies of the catalysts (adapted from reference 82; copyright 2012 American Chemical Society. Adapted with permission).

on a broader evaluation.

In a simpler fashion, one can say that sustainability leans on three pillars: social, environmental and economic. As to be defined sustainable, a process must be cost effective, bring benefits to the society surrounding the company, and not damage the environment. If a process is socially and environmentally correct but not economically viable, it can be defined as bearable, but not sustainable. If it only meets the economic and environmental requirements, it is viable, but not sustainable. And finally, it is economically and socially correct, it will be equitable. While defining cost effectiveness is an easy task, assigning a process as socially and environmentally correct is more abstract and depends on discussions, normative and points of view.

Using biomass as feedstock for production of chemicals and fuel has always raised two important, fair and fundamental concerns: Can edibles be used for chemical conversion? Is it acceptable to use productive lands to grow feedstock for industry instead of food? Food is indeed the first and vital priority in any society and the population grown must be taken in consideration. Hence, edibles should not be considered for industrial feedstock and food crops should not be replaced by feedstock crops. An industry feedstock crop depends, then, on available fertile land that are not necessary at that moment for food crops. Assuming large-scale production of feedstock biomass, not many countries will have lands that fit with these requirements and, therefore, a conclusion is that biomass feedstock will not be available anywhere (just like petroleum is not). Brazil is a successful example, showing that food and feedstock crops can coexist.

Development of agronomy and cultivation techniques has played a leading role on this matter. As shown in Figure 16, from 1978 to 2012, the crops production increased by 4 folds, while the area cultivated almost did not change. A continental country like Brazil, with plenty of fertile land, can manage to efficiently produce food and biomass for industry, and this could bring social and economic benefits. With a good management of the lands, and avoiding the use of unexplored forest areas, the feedstock crops can also meet the environmental pillar of the sustainability. From the environmental point of view, using biomass over oil as industrial feedstock leads to a significant reduction in the emission of greenhouse effect gases. ${ }^{97}$ For instance, this reduction can reach $70 \%$ for the production of acrylic acid, adipic acid, and 1,4-butadiene, from 20 to $80 \%$ for isobutene, and $50 \%$ for polyethylene. ${ }^{97}$

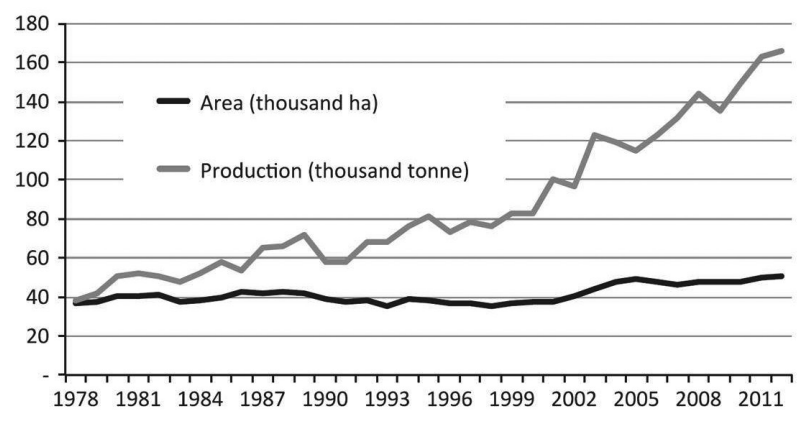

Figure 16. Cultivated area and production of cereals and oil crops in Brazil (reproduced from reference 155).

Example of countries that are good candidates for growing biomass feedstocks can be taken by mapping the current sugar cane growing areas (Figure 17). Besides Brazil, many other countries in Latin America, Southeast Asia and Africa have been cultivating sugar cane (Figure 17). Still from the social point of view, the raise of efficient biorefineries could represent an opportunity for underdevelopment countries, and consequently, a big change in worldwide income distribution. Ideally, for sake of the feedstock management, the biorefinery must be close to the biomass crops and, therefore, promoting industrialization of the areas surrounding the fields.

Discussion concerning price and cost effectiveness of biomass derived products and processes cannot be 


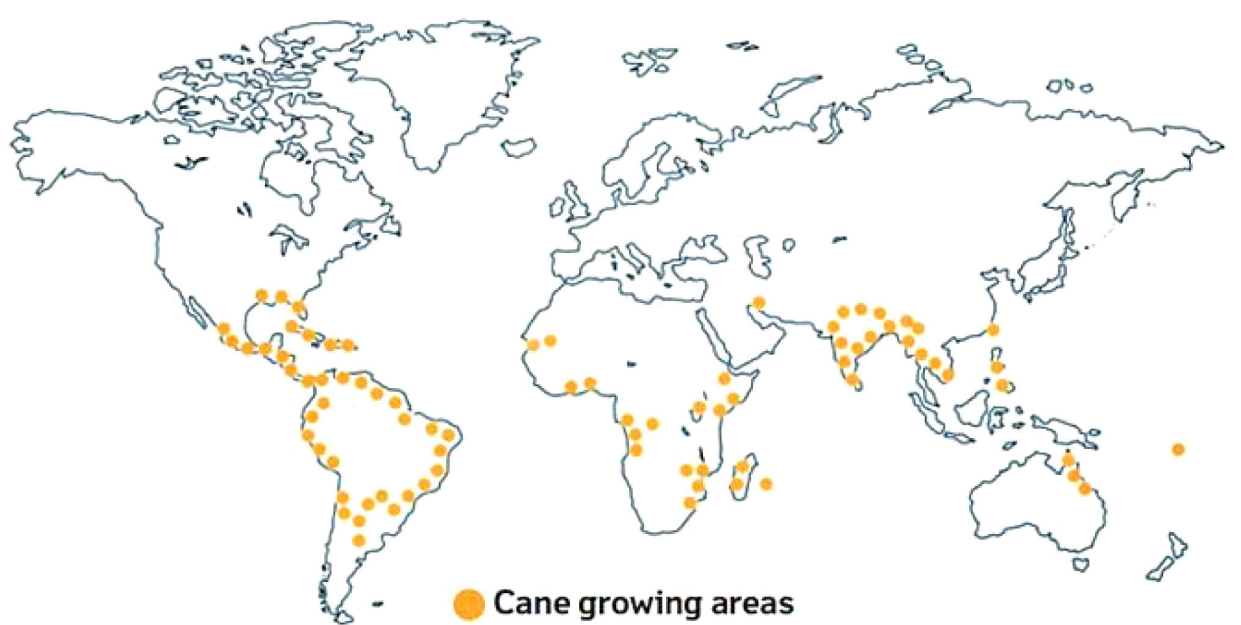

Figure 17. Worldwide sugar cane crops in 2012 (reproduced from reference 156).

precisely done yet. With few exceptions, biomass-derived products are still not produced in large scale and the biorefineries have not been established yet. Therefore, feedstock availability and management is still not at its best, as well as the processing development. However, economical and chemical studies can help guiding to find the cost-effective biomass-derived chemicals. As shown in Figure 4, processing oil and biomass require different reactions and processes and, therefore, it is plausible that some products will be more cost effective from petroleum while for others, biomass can be preferred as feedstock.

Feedstock prices, as well as the type and number of reactions required for conversion are determinant factors in estimating the economic viability of obtaining a chemical from biomass. Figure 18 illustrates the relative price of selected products when obtained from fossil fuel or biomass. Although this comparison was made before the recent drop of the petroleum price to ca. 50 US dollars in 2016, it still illustrates an important trend of products that are worthy producing from renewable sources.

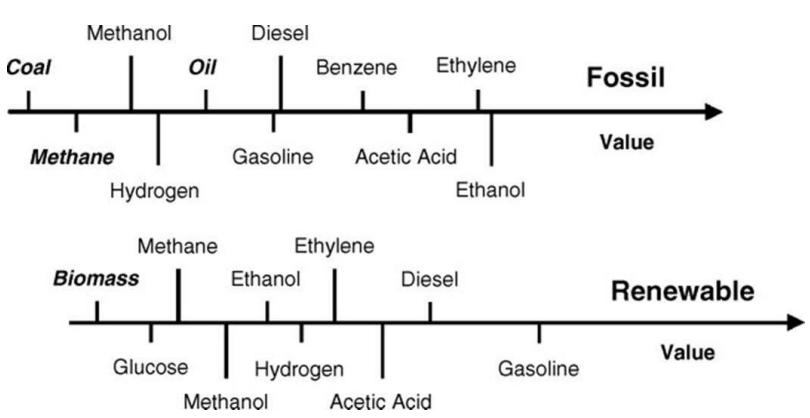

Figure 18. Relative prices of selected chemicals when produced from renewable or fossil feedstocks (reprinted from reference 94; copyright 2007 by John Wiley \& Sons, Inc.; Reproduced with permission).

Besides the feedstock price, one can generalize that the final price of the product will also depend on the extent of the chemical modifications. Hence, the higher the chemical similarity between feedstock and products, the lower the required chemical reactions and modifications, and consequently, the lower the processing price. Following this approach, in Figure 19, the $\mathrm{O} / \mathrm{C}$ and $\mathrm{H} / \mathrm{C}$ ratio between renewable and non-renewable feedstocks, chemicals and fuels are compared. Crude oil and methane (main component in the natural gas) present an $\mathrm{O} / \mathrm{C}$ ratio of zero, while for the biomass major components (cellulose and hemicellulose), the ratio is close to 0.8 . The $\mathrm{O} / \mathrm{C}$ ratio for fuel (gasoline, diesel, kerosene and even biodiesel) is, perhaps, much closer to the fossil fuels than to the biomass derivatives. Therefore, according to Figure 19, producing fuels from fossil feedstocks would be advantageous due to the lower number of chemical modification steps and to the atom economy, which is in agreement with the scenario of modern chemical industry.

The ethanol case in Figure 19 is another example in agreement with the current scenario. According to the figure, ethanol is half way between glucose and oil and would be cost effective if it was produced from both fossil fuels and biomass. Indeed, ethanol is cost effective in both cases, which will depend on the petroleum and sugar cane (or sweetcorn) prices in the region where it is produced. ${ }^{157}$ Many chemicals, currently obtained from fossil fuels would fit, in Figure 19, closer to biomass or half way with fossil fuels. For instance, according to the figure, methanol, ${ }^{97}$ acetic acid, ${ }^{97}$ butanol, ${ }^{97}$ terephthalic acid, ${ }^{97}$ ethanol, ${ }^{97}$ and paracetamol $1^{158,159}$ could be economically viable if produced from a renewable feedstock. The correlations shown in Figures 18 and 19 must be taken in consideration for establishing the chemical routes to be employed within the biorefineries.

At this point, it is reasonable to say that considering the currently available technology, biomass would be 


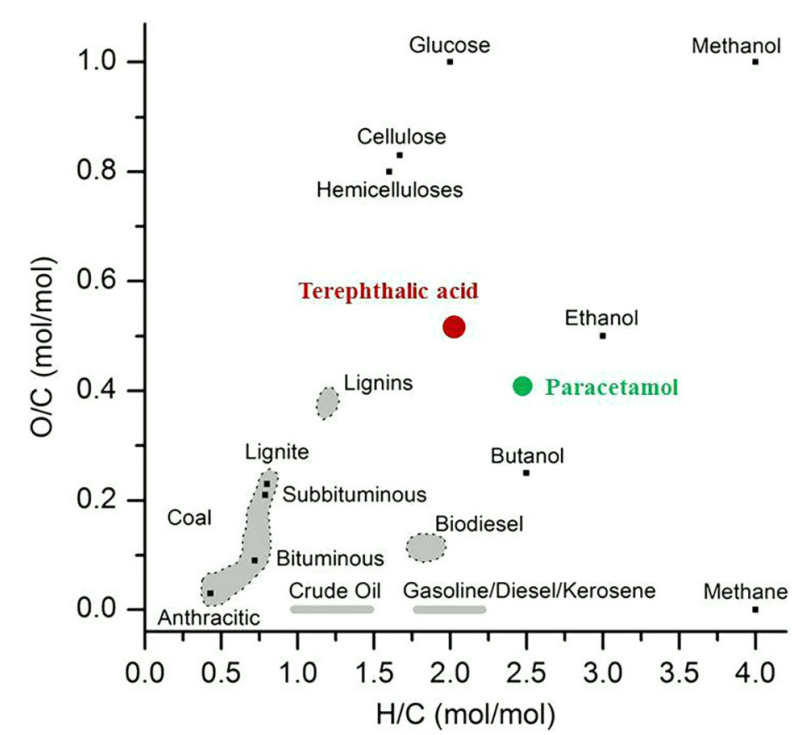

Figure 19. O/C molar ratio for crude oil, biomass fractions, and typical products related to chemical and petrochemical industry (adapted from reference 95; reproduced with permission from The Royal Society of Chemistry).

more suitable for producing chemicals, while hydrocarbon based fuels must be produced from fossil fuels. There are indeed mixed opinions on the biofuels. For instance, in 2012, the Nobel Prize laureate Hartmut Michel stated that the future of transportation might be electric, since the combination of photovoltaic cells, electric battery and electric engine uses the land more efficiently than the combination of biomass, biofuel and mechanic engine. ${ }^{160}$ Goldemberg and co-workers ${ }^{161}$ claim that these conclusions are simplistic and essentially based on the comparison of efficiency of photosynthesis in converting solar radiation (below 6\%) with the efficiency of photovoltaic cells (about 15\%).

Certainly, the future of transportation lies on the development of voltaic cells (fuel or photovoltaic cells) and electric engines, which are at least twice more efficient than the mechanic engine. However, we are still decades far from obtaining reliable systems able to fully replace the traditional engines. Until then, for most countries, petroleum-derived fuels will probably be the most attractive and cost effective fuel.

Examples like Brazil, in which a biofuel is responsible for $1 / 3$ of the fuels for light and medium vehicles, ${ }^{157}$ are hard to be followed. As mentioned before, only few countries in the world would be able to grow such an amount of vegetable feedstock to fulfill the local demand. Due to its specific composition and high cost, jet fuel is probably the only exception of traditional fuel that might become cost effective if produced from biomass. ${ }^{162,163}$ Recently, joint efforts by São Paulo Research Foundation (FAPESP), Boeing and Embraer let to the implementation of a road mapping methodology aiming to reach a consensus on action plan priorities (gaps and barriers) in order to promote the use of sustainable biofuels for aviation. ${ }^{16}$

At the current stage of development, biomass conversion is still not sustainable, but there is a huge potential, if the feedstock crops are expanded, the chemical processes further developed and if more integration between biorefinery and chemical industry is created. Certainly, chemical industry cannot rely on petroleum for many more generations, and therefore it is time to explore more intensively the renewable alternatives. Several industries are investing in biobased processes, which can be found under different Technology Readiness Level (TRL), as illustrated in Table 2 for some of the molecules discussed in this account (the complete table can be found in the literature) ${ }^{97}$

\section{Conclusions}

Lignocellulosic biomass has a huge potential to be established as an industrial feedstock for the chemical industry. Its simple composition allows a rational processing into several chemical for application such as fuels, industrial solvents, precursors for pharmaceutical industry, and monomers for resins, fibers and plastics. Biomass as feedstock can delivery to industry some of the same products obtained from petroleum and also other chemicals with similar application to those obtained from petroleum. However, the use of biomass feedstock is still not cost competitive with petroleum and further development on chemical processes are required. In the last years, it has been observed an enormous advance on the chemical conversion of biomass, with solvent systems that allowed better reaction performances and also by replacing homogeneous catalysts with heterogeneous ones. Additionally, a better understanding of the reaction mechanisms led to a more rational designing of catalysts. Concerning heterogeneous catalysis, the challenge lies in processes integration and development of catalytic systems that allow multiple reactions in a single reactor (onepot regime, or bi- and multifunctional catalysts).

Although biomass conversion is still not sustainable, as it becomes cost effective and the biorefineries are established, it is expected that the economy on underdevelopment countries, where biomass in cultivated, is developed, and therefore, an important change in the worldwide income distribution.

\section{Acknowledgments}

J. M. R. G. thanks FAPESP for the Young Investigator Award (process No. 2016/02128-2). 
Table 2. Status and industrial activity for bio-based products (adapted from reference 97)

\begin{tabular}{|c|c|c|c|c|c|c|}
\hline \multirow{2}{*}{ Product } & \multirow{2}{*}{$\operatorname{Max} \operatorname{TRL}^{\mathrm{a}}$} & \multicolumn{4}{|c|}{ Production facilities $^{\mathrm{b}}$} & \multirow{2}{*}{ Leading companies } \\
\hline & & EU & NA & SA & Asia & \\
\hline Sorbitol & $8-9$ & & M & & $\mathrm{M}$ & ADM, Roquette \\
\hline Ethylene glycol & $8-9$ & $\mathrm{R}$ & & & M & Global Biochem, Greencol Taiwan Corporation, etc \\
\hline Furfural & $8-9$ & $\mathrm{D}$ & M & & & Central Romana Corporation \\
\hline Furfuryl alcohol & $8-9$ & M & & & M & TransFuran Chemicals, Zibo Shuangyu Chemical \\
\hline Lactic acid & $8-9$ & M & M & M & M & Chongqing Bofei Biochemical Products, etc \\
\hline Xylitol & $8-9$ & M & $\mathrm{R}$ & & M & DuPont Danisco, Roquette \\
\hline Acetaldehyde & $8-9$ & M & & & & Sekab \\
\hline $\mathrm{PE}$ & 8 & & & M & & Braskem \\
\hline Succinic acid & 8 & M & M & & & Myriant, Reverdia, Succinity, BioAmber \\
\hline Ethyl lactate & $6-7$ & & $\mathrm{D}$ & & & Vertec BioSolvents \\
\hline Furan & $6-7$ & & $\mathrm{D}$ & & & Pennakem \\
\hline Levulinic acid & $6-7$ & $\mathrm{D}$ & $\mathrm{R}$ & & $\mathrm{D}$ & Segetis, Zibo Shuangyu Chemical \\
\hline Methyl THF & $6-7$ & & $\mathrm{D}$ & & & Pennakem \\
\hline THF & 5 & $\mathrm{R}$ & & & & Davy Process Technology, Pennakem \\
\hline $5-\mathrm{HMF}$ & 5 & $\mathrm{R}$ & & & & AVA Biochem \\
\hline Acrylic acid & 5 & $\mathrm{R}$ & $\mathrm{R}$ & & & ADM, Arkema, BASF, OPX Bio \\
\hline Adipic acid & 5 & & $\mathrm{R}$ & & & BioAmber, DSM, Rennovia, Verdezyne \\
\hline Benzene & 5 & & $\mathrm{R}$ & & & Virent \\
\hline FDCA & 5 & $\mathrm{R}$ & & & & Avantium \\
\hline Formic acid & 5 & $\mathrm{R}$ & $\mathrm{R}$ & & & Biofine Technology \\
\hline Glucaric acid & 5 & & $\mathrm{R}$ & & & Rennovia, Rivertop Renewables \\
\hline Jet fuel & 5 & & $\mathrm{R}$ & & & Gevo, Virent \\
\hline$p$-Xylene & 5 & & $\mathrm{R}$ & & & Gevo, Virent \\
\hline PET & 5 & & & & $\mathrm{R}$ & Toray \\
\hline Terephthalic acid & 5 & & $\mathrm{R}$ & & $\mathrm{R}$ & Toray, Virent \\
\hline Furoic acid & 5 & & $\mathrm{R}$ & & & xF Technologies \\
\hline Furanoate esters & 4 & & $\mathrm{R}$ & & & xF Technologies \\
\hline Iso-pentanol & 4 & & $\mathrm{R}$ & & & Saffron Eagle Biofuels \\
\hline Fumaric acid & $3-4$ & & $\mathrm{R}$ & & & Myriant \\
\hline Glycolic acid & $3-4$ & $\mathrm{R}$ & & & & Metabolic Explorer \\
\hline Methyl levulinate & $3-4$ & $\mathrm{R}$ & & & & Avantium \\
\hline
\end{tabular}

aTRL: Technology Readiness Level; TRL 1: basic principles observed; TRL 2: technology concept formulated; TRL 3: experimental proof of concept; TRL 4: technology validated in lab; TRL 5: technology validated in relevant environment (industrially relevant environment in the case of key enabling technologies); TRL 6: technology demonstrated in relevant environment (industrially relevant environment in the case of key enabling technologies); TRL 7: system prototype demonstration in operational environment; TRL 8: system complete and qualified; TRL 9: actual system proven in operational environment (competitive manufacturing in the case of key enabling technologies; ${ }^{\mathrm{b}} \mathrm{M}$ : manufacturing, D: demonstration or R: research/pilot; PE: polyethylene; THF: tetrahydrofuran; 5-HMF: 5-hydroxymethylfurfural; FDCA: 2,5-furandicarboxylic acid; PET: polyethylenetherephthalate.

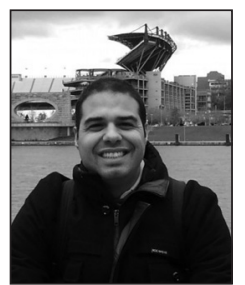

Jean Marcel R. Gallo obtained the PhD in Sciences in a cotutelle program between the University of the Eastern Piedmont (Italy) and the State University of Campinas (Brazil). He is a Professor of Inorganic Chemistry in the Chemistry Department at the Federal University of São Carlos (Brazil), where he leads the Group of Renewable Energy, Nanotechnology, and Catalysis (GreenCat) since 2014. In 2016 he received the FAPESP Young Investigator Award to develop his research on fundamental and applied heterogeneous catalysis applied to biomass conversion.

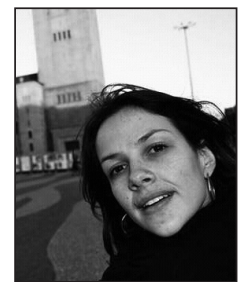

Marilia A. Trapp received her $P h D$ degree in 2016 in the Department of Chemistry at the Federal University of São Carlos. Part of her research project was developed at The Max Planck Institute for Chemical Ecology (Germany), where she is now a CAPESHumboldt-funded post-doctoral fellow on the topic of chemical ecology of crop cultures. Her general interests are focused on understanding ecological relationships in order to improve crop productivity. 


\section{References}

1. Davis, S. C.; Diegel, S. W.; Boundy, R. G.; Transportation Energy Data Book, 34 ${ }^{\text {rd }}$ ed.; Oak Ridge National Laboratory: Oak Ridge, Tenn, 2013.

2. Institute for Energy Research, http://instituteforenergyresearch. org/topics/encyclopedia/petroleum/ accessed in January 2017.

3. Center for Climate and Energy Solution (C2ES), http://www. c2es.org/energy/use/transportation accessed in January 2017.

4. Han, S.; Kuchar, E.; Karlowicz-Bodalska, K.; Kutycka, E.; Miskiewicz, K.; Nitsch-Osuch, A.; Trop. J. Pharm. Res. 2014, 13, 617 .

5. Tsoler, U. In Handbook of Detergents, Part F: Production; Zoller, U.; Sosis, P., eds.; CRC press: New York, 2009.

6. Plastics: The Facts 2015, Association of Plastic Manufacturers, 2015 http://www.plasticseurope.org/documents/ document/20151216062602-plastics_the_facts_2015_ final_30pages_14122015.pdf accessed in January 2017.

7. Annual Energy Review, U.S. Energy Information Administration: http://www.eia.gov/cfapps/ipdbproject/ iedindex $3 . \mathrm{cfm}$ ?tid=5\&pid=54\&aid=2, 2009.

8. The CIA world factbook, Central Intelligence Agency: https:// www.cia.gov/library/publications/the-world-factbook/index. html, Washington, DC, 2013-14.

9. Aguilera, R. F.; Eggert, R. G.; Lagos, C. C. G.; Tilton, J. E.; Energy J. 2009, 30, 141.

10. Rosillo-Calle, F.; Cortez, L. A. B.; Biomass Bioenergy 1998, 14, 115 .

11. Verardi, A.; Bari, I. D.; Ricca, E.; Calabrò, V. In Bioethanol; Lima, M. A. P.; Pardo, A., eds.; INTECH: Rijeka, 2012.

12. Bozell, J. J.; Petersen, G. R.; Green Chem. 2010, 12, 539.

13. Alamillo, R.; Tucker, M.; Chia, M.; Pagan-Torres, Y.; Dumesic, J.; Green Chem. 2012, 14, 1413.

14. Roman-Leshkov, Y.; Barrett, C. J.; Liu, Z. Y.; Dumesic, J. A.; Nature 2007, 447, 982.

15. Wang, D.; Osmundsen, C. M.; Taarning, E.; Dumesic, J. A.; ChemCatChem 2013, 5, 2044.

16. Pacheco, J. J.; Labinger, J. A.; Sessions, A. L.; Davis, M. E.; ACS Catal. 2015, 5, 5904.

17. Orazov, M.; Davis, M. E.; Chem. Sci. 2016, 7, 2264.

18. Cheng, Y.-T.; Huber, G. W.; Green Chem. 2012, 14, 3114.

19. Gorbanev, Y. Y.; Klitgaard, S. K.; Woodley, J. M.; Christensen, C. H.; Riisager, A.; ChemSusChem 2009, 2, 672.

20. Davis, S. E.; Ide, M. S.; Davis, R. J.; Green Chem. 2013, 15, 17.

21. Davis, S. E.; Zope, B. N.; Davis, R. J.; Green Chem. 2012, 14 , 143.

22. Davis, S. E.; Houk, L. R.; Tamargo, E. C.; Datye, A. K.; Davis, R. J.; Catal. Today 2011, 160, 55.

23. Wagner, J. R.; Multilayer Flexible Packaging, $1^{\text {st }}$ ed.; Elsevier Science: Oxford, 2010.
24. Van de Vyver, S.; Roman-Leshkov, Y.; Catal. Sci. Technol. 2013, $3,1465$.

25. Lee, J.; Saha, B.; Vlachos, D. G.; Green Chem. 2016, 18, 3815.

26. Alonso, D. M.; Gallo, J. M. R.; Mellmer, M. A.; Wettstein, S. G.; Dumesic, J. A.; Catal. Sci. Technol. 2013, 3, 927.

27. Alonso, D. M.; Wettstein, S. G.; Dumesic, J. A.; Green Chem. 2013, 15, 584.

28. Wettstein, S. G.; Bond, J. Q.; Alonso, D. M.; Pham, H. N.; Datye, A. K.; Dumesic, J. A.; Appl. Catal., B 2012, 117, 321.

29. Wettstein, S. G.; Alonso, D. M.; Chong, Y. X.; Dumesic, J. A.; Energy Environ. Sci. 2012, 5, 8199.

30. Mai, E. F.; Machado, M. A.; Davies, T. E.; Lopez-Sanchez, J. A.; da Silva, V. T.; Green Chem. 2014, 16, 4092.

31. Sen, S. M.; Gurbuz, E. I.; Wettstein, S. G.; Alonso, D. M.; Dumesic, J. A.; Maravelias, C. T.; Green Chem. 2012, 14, 3289.

32. Gurbuz, E. I.; Wettstein, S. G.; Dumesic, J. A.; ChemSusChem 2012, 5, 383.

33. Alonso, D. M.; Wettstein, S. G.; Dumesic, J. A.; Chem. Soc. Rev. 2012, 41, 8075.

34. Serrano-Ruiz, J. C.; Dumesic, J. A.; Energy Environ. Sci. 2011, $4,83$.

35. Pharn, H. N.; Pagan-Torres, Y. J.; Serrano-Ruiz, J. C.; Wang, D.; Dumesic, J. A.; Datye, A. K.; Appl. Catal., A 2011, 397, 153.

36. Pagan-Torres, Y. J.; Gallo, J. M. R.; Wang, D.; Pham, H. N.; Libera, J. A.; Marshall, C. L.; Elam, J. W.; Datye, A. K.; Dumesic, J. A.; ACS Catal. 2011, 1, 1234.

37. Gurbuz, E. I.; Alonso, D. M.; Bond, J. Q.; Dumesic, J. A.; ChemSusChem 2011, 4, 357.

38. Braden, D. J.; Henao, C. A.; Heltzel, J.; Maravelias, C. T.; Dumesic, J. A.; Green Chem. 2011, 13, 1755.

39. Bond, J. Q.; Wang, D.; Alonso, D. M.; Dumesic, J. A.; J. Catal. 2011, 281, 290.

40. Alonso, D. M.; Wettstein, S. G.; Bond, J. Q.; Root, T. W.; Dumesic, J. A.; ChemSusChem 2011, 4, 1078.

41. Serrano-Ruiz, J. C.; Wang, D.; Dumesic, J. A.; Green Chem. 2010, 12, 574 .

42. Bond, J. Q.; Alonso, D. M.; West, R. M.; Dumesic, J. A.; Langmuir 2010, 26, 16291.

43. Bond, J. Q.; Alonso, D. M.; Wang, D.; West, R. M.; Dumesic, J. A.; Science 2010, 327, 1110.

44. Tolborg, S.; Sadaba, I.; Osmundsen, C. M.; Fristrup, P.; Holm, M. S.; Taarning, E.; ChemSusChem 2015, 8, 613.

45. Holm, M. S.; Pagán-Torres, Y. J.; Saravanamurugan, S.; Riisager, A.; Dumesic, J. A.; Taarning, E.; Green Chem. 2012, $14,702$.

46. West, R. M.; Holm, M. S.; Saravanamurugan, S.; Xiong, J.; Beversdorf, Z.; Taarning, E.; Christensen, C. H.; J. Catal. 2010, $269,122$.

47. Holm, M. S.; Saravanamurugan, S.; Taarning, E.; Science 2010, 328,602 .

48. Sitthisa, S.; Resasco, D. E.; Catal. Lett. 2011, 141, 784. 
49. Alonso-Fagundez, N.; Agirrezabal-Telleria, I.; Arias, P. L.; Fierro, J. L. G.; Mariscal, R.; Granados, M. L.; RSC Adv. 2014, 4, 54960 .

50. Verdeguer, P.; Merat, N.; Rigal, L.; Gaset, A.; J. Chem. Technol. Biotechnol. 1994, 61, 97.

51. Serrano-Ruiz, J. C.; Luque, R.; Sepulveda-Escribano, A.; Chem. Soc. Rev. 2011, 40, 5266.

52. West, R. M.; Liu, Z. Y.; Peter, M.; Gartner, C. A.; Dumesic, J. A.; J. Mol. Catal. A: Chem. 2008, 296, 18.

53. Simonetti, D. A.; Dumesic, J. A.; ChemSusChem 2008, 1, 725.

54. Chheda, J. N.; Dumesic, J. A.; Catal. Today 2007, 123, 59.

55. Climent, M. J.; Corma, A.; Iborra, S.; Green Chem. 2014, 16, 516.

56. Sacia, E. R.; Balakrishnan, M.; Deaner, M. H.; Goulas, K. A.; Toste, F. D.; Bell, A. T.; ChemSusChem 2015, 8, 1726.

57. Davis, M. E.; Top. Catal. 2015, 58, 405.

58. Green, S. K.; Patet, R. E.; Nikbin, N.; Williams, C. L.; Chang, C.-C.; Yu, J.; Gorte, R. J.; Caratzoulas, S.; Fan, W.; Vlachos, D. G.; Dauenhauer, P. J.; Appl. Catal., B 2016, 180, 487.

59. Li, Y.-P.; Head-Gordon, M.; Bell, A. T.; ACS Catal. 2016, 6, 5052 .

60. Williams, C. L.; Chang, C.-C.; Do, P.; Nikbin, N.; Caratzoulas, S.; Vlachos, D. G.; Lobo, R. F.; Fan, W.; Dauenhauer, P. J.; ACS Catal. 2012, 2, 935.

61. Williams, C. L.; Vinter, K. P.; Chang, C.-C.; Xiong, R.; Green, S. K.; Sandler, S. I.; Vlachos, D. G.; Fan, W.; Dauenhauer, P. J.; Catal. Sci. Technol. 2016, 6, 178.

62. Williams, C. L.; Vinter, K. P.; Patet, R. E.; Chang, C.-C.; Nikbin, N.; Feng, S.; Wiatrowski, M. R.; Caratzoulas, S.; Fan, W.; Vlachos, D. G.; Dauenhauer, P. J.; ACS Catal. 2016, 6, 2076.

63. Rinaldi, R.; Jastrzebski, R.; Clough, M. T.; Ralph, J.; Kennema, M.; Bruijnincx, P. C. A.; Weckhuysen, B. M.; Angew. Chem., Int. Ed. 2016, 55, 8164.

64. Ferrini, P.; Rinaldi, R.; Angew. Chem., Int. Ed. 2014, 53, 8634.

65. Verboekend, D.; Liao, Y.; Schutyser, W.; Sels, B. F.; Green Chem. 2016, 18, 297.

66. Wang, X.; Rinaldi, R.; Angew. Chem., Int. Ed. 2013, 52, 11499.

67. Jongerius, A. L.; Bruijnincx, P. C. A.; Weckhuysen, B. M.; Green Chem. 2013, 15, 3049.

68. Negahdar, L.; Gonzalez-Quiroga, A.; Otyuskaya, D.; Toraman, H. E.; Liu, L.; Jastrzebski, J. T. B. H.; Van Geem, K. M.; Marin, G. B.; Thybaut, J. W.; Weckhuysen, B. M.; ACS Sustainable Chem. Eng. 2016, 4, 4974.

69. Ji, N.; Wang, X.; Weidenthaler, C.; Spliethoff, B.; Rinaldi, R.; ChemCatChem 2015, 7, 960.

70. Xu, C.; Arancon, R. A. D.; Labidi, J.; Luque, R.; Chem. Soc. Rev. 2014, 43, 7485.

71. Roman-Leshkov, Y.; Chheda, J. N.; Dumesic, J. A.; Science 2006, 312, 1933.

72. Roman-Leshkov, Y.; Dumesic, J. A.; Top. Catal. 2009, 52, 297.

73. Dumesic, J.A.; Gallo, J.M. R.; Alonso, D. M.; US20140107355A1 2014.
74. Gallo, J. M. R.; Alonso, D. M.; Mellmer, M. A.; Dumesic, J. A.; Green Chem. 2013, 15, 85.

75. Brown, D. W.; Floyd, A. J.; Kinsman, R. G.; Roshanali, Y.; J. Chem. Technol. Biotechnol. 1982, 32, 920.

76. Musau, R. M.; Munavu, R. M.; Biomass 1987, 13, 67.

77. Vandam, H. E.; Kieboom, A. P. G.; Vanbekkum, H.; StarchStarke 1986, 38, 95.

78. Mushrif, S. H.; Caratzoulas, S.; Vlachos, D. G.; Phys. Chem. Chem. Phys. 2012, 14, 2637.

79. Zhao, H. B.; Holladay, J. E.; Brown, H.; Zhang, Z. C.; Science 2007, 316, 1597.

80. Jadhav, H.; Taarning, E.; Pedersen, C. M.; Bols, M.; Tetrahedron Lett. 2012, 53, 983.

81. Binder, J. B.; Raines, R. T.; J. Am. Chem. Soc. 2009, 131, 1979.

82. Pagan-Torres, Y. J.; Wang, T. F.; Gallo, J. M. R.; Shanks, B. H.; Dumesic, J. A.; ACS Catal. 2012, 2, 930.

83. Balakrishnan, M.; Sacia, E. R.; Bell, A. T.; Green Chem. 2012, 14, 1626.

84. Sacia, E. R.; Balakrishnan, M.; Bell, A. T.; J. Catal. 2014, 313, 70.

85. Luterbacher, J. S.; Alonso, D. M.; Rand, J. M.; QuestellSantiago, Y. M.; Yeap, J. H.; Pfleger, B. F.; Dumesic, J. A.; ChemSusChem 2015, 8, 1317.

86. Mellmer, M. A.; Sener, C.; Gallo, J. M.; Luterbacher, J. S.; Alonso, D. M.; Dumesic, J. A.; Angew. Chem., Int. Ed. Engl. 2014, 53, 11872.

87. Luterbacher, J. S.; Rand, J. M.; Alonso, D. M.; Han, J.; Youngquist, J. T.; Maravelias, C. T.; Pfleger, B. F.; Dumesic, J. A.; Science 2014, 343, 277.

88. Gurbuz, E. I.; Gallo, J. M.; Alonso, D. M.; Wettstein, S. G.; Lim, W. Y.; Dumesic, J. A.; Angew. Chem., Int. Ed. Engl. 2013, 52, 1270.

89. Gallo, J. M. R.; Alamillo, R.; Dumesic, J. A.; J. Mol. Catal. A: Chem., in press, DOI: 10.1016/j.molcata.2016.01.005.

90. Mellmer, M. A.; Gallo, J. M. R.; Alonso, D. M.; Dumesic, J. A.; ACS Catal. 2015, 5, 3354.

91. Nikbin, N.; Caratzoulas, S.; Vlachos, D. G.; ChemCatChem 2012, 4, 504.

92. Mellmer, M. A.; Alonso, D. M.; Luterbacher, J. S.; Gallo, J. M. R.; Dumesic, J. A.; Green Chem. 2014, 16, 4659.

93. Gross, A. S.; Bell, A. T.; Chu, J. W.; Phys. Chem. Chem. Phys. 2012, 14, 8425.

94. Rass-Hansen, J.; Falsig, H.; Jørgensen, B.; Christensen, C. H.; J. Chem. Technol. Biotechnol. 2007, 82, 329.

95. Rinaldi, R.; Schuth, F.; Energ. Environ. Sci. 2009, 2, 610.

96. Teong, S. P.; Yi, G. S.; Zhang, Y. G.; Green Chem. 2014, 16, 2015.

97. Taylor, R.; Nattrass, L.; Alberts, G.; Robson, P.; Chudziak, C.; Bauen, A.; Libelli, I. M.; Lotti, G.; Prussi, M.; Nistri, R.; Chiaramonti, D.; Contreras, A. L.; Bos, H.; Eggink, G.; Springer, J.; Bakker, R.; van Ree, R.; From the Sugar Platform to Biofuels and Biochemicals; European Union: London, 2015. 
98. Lange, J. P.; Angew. Chem., Int. Ed. Engl. 2015, 54, 13186.

99. Bakare, I. A.; Muraza, O.; Kurniawan, T.; Yamani, Z. H.; Shafei, E. N.; Punetha, A. K.; Choi, K.-H.; Yokoi, T.; Microporous Mesoporous Mater. 2016, 233, 93.

100. Xiong, H.; Pham, H. N.; Datye, A. K.; Green Chem. 2014, 16 , 4627.

101. Ravenelle, R. M.; Schüßler, F.; D’Amico, A.; Danilina, N.; van Bokhoven, J. A.; Lercher, J. A.; Jones, C. W.; Sievers, C.; J. Phys. Chem. C 2010, 114, 19582.

102. Lutz, W.; Toufar, H.; Kurzhals, R.; Suckow, M.; Adsorption 2005, 11, 405.

103. Zapata, P. A.; Faria, J.; Ruiz, M. P.; Jentoft, R. E.; Resasco, D. E.; J. Am. Chem. Soc. 2012, 134, 8570.

104. Ding, L.; Zheng, Y.; Hong, Y.; Ring, Z.; Microporous Mesoporous Mater. 2007, 101, 432.

105. Valle, B.; Gayubo, A. G.; Alonso, A.; Aguayo, A. T.; Bilbao, J.; Appl. Catal., B 2010, 100, 318.

106. Deng, C.; Zhang, J.; Dong, L.; Huang, M.; Bin, L.; Jin, G.; Gao, J.; Zhang, F.; Fan, M.; Zhang, L.; Gong, Y.; Sci. Rep. 2016, 6, 23382.

107. Xiong, H.; Schwartz, T. J.; Andersen, N. I.; Dumesic, J. A.; Datye, A. K.; Angew. Chem., Int. Ed. Engl. 2015, 54, 7939.

108. Gallo, J. M. R.; Alonso, D. M.; Mellmer, M. A.; Yeap, J. H.; Wong, H. C.; Dumesic, J. A.; Top. Catal. 2013, 1.

109. Choudhary, V.; Pinar, A. B.; Sandler, S. I.; Vlachos, D. G.; Lobo, R. F.; ACS Catal. 2011, 1, 1724.

110. Pacheco, J. J.; Davis, M. E.; Proc. Natl. Acad. Sci. USA 2014, $111,8363$.

111. Gürbüz, E. I.; Gallo, J. M. R.; Alonso, D. M.; Wettstein, S. G.; Lim, W. Y.; Dumesic, J. A.; Angew. Chem., Int. Ed. 2013, 52, 1270.

112. Gallo, J. M. R.; Alonso, D. M.; Mellmer, M. A.; Dumesic, J. A.; Green Chem. 2013, 15, 85.

113. Alonso, D. M.; Wettstein, S. G.; Mellmer, M. A.; Gürbüz, E. I. Dumesic, J. A.; Energy Environ. Sci. 2013, 6, 76.

114. Crisci, A. J.; Tucker, M. H.; Lee, M. Y.; Jang, S. G.; Dumesic, J. A.; Scott, S. L.; ACS Catal. 2011, 1, 719.

115. Yu, F.; Thomas, J.; Smet, M.; Dehaen, W.; Sels, B. F.; Green Chem. 2016, 18, 1694.

116. Tucker, M. H.; Crisci, A. J.; Wigington, B. N.; Phadke, N.; Alamillo, R.; Zhang, J. P.; Scott, S. L.; Dumesic, J. A.; ACS Catal. 2012, 2, 1865.

117. Alamillo, R.; Crisci, A. J.; Gallo, J. M.; Scott, S. L.; Dumesic, J. A.; Angew. Chem., Int. Ed. Engl. 2013, 52, 10349.

118. Lange, J. P.; van de Graaf, W. D.; Haan, R. J.; ChemSusChem 2009, 2, 437.

119. Gürbüz, E. I.; Wettstein, S. G.; Dumesic, J. A.; ChemSusChem 2012, 5, 383.

120. Kruger, J. S.; Nikolakis, V.; Vlachos, D. G.; Curr. Opin. Chem. Eng. 2012, 1, 312.

121. Nikolla, E.; Roman-Leshkov, Y.; Moliner, M.; Davis, M. E.; ACS Catal. 2011, 1, 408.
122. Moliner, M.; Roman-Leshkov, Y.; Davis, M. E.; Proc. Natl. Acad. Sci. USA 2010, 107, 6164.

123. Enslow, K. R.; Bell, A. T.; ChemCatChem 2015, 7, 479.

124. Ayame, A.; Sawada, G.; Sato, H.; Zhang, G.; Ohta, T.; Izumizawa, T.; Appl. Catal. 1989, 48, 25.

125. Melchor, A.; Garbowski, E.; Mathieu, M.-V.; Primet, M.; J. Chem. Soc., Faraday Trans. 1 1986, 82, 1893.

126. Sang, H.; Chu, H. Y.; Lunsford, J. H.; Catal. Lett. 1994, 26, 235.

127. Clet, G.; Goupil, J. M.; Cornet, D.; Bull. Soc. Chim. Fr. 1997, 134, 223.

128. Zhang, Z. C.; Beard, B. C.; Appl. Catal., A 1999, 188, 229.

129. Oh, H. S.; Yang, J. H.; Costello, C. K.; Wang, Y. M.; Bare, S. R.; Kung, H. H.; Kung, M. C.; J. Catal. 2002, 210, 375.

130. Wang, T. F.; Pagan-Torres, Y. J.; Combs, E. J.; Dumesic, J. A.; Shanks, B. H.; Top. Catal. 2012, 55, 657.

131. Enslow, K. R.; Bell, A. T.; Catal. Sci. Technol. 2015, 5, 2839.

132. Román-Leshkov, Y.; Davis, M. E.; ACS Catal. 2011, 1, 1566.

133. Roman-Leshkov, Y.; Moliner, M.; Labinger, J. A.; Davis, M. E.; Angew. Chem., Int. Ed. Engl. 2010, 49, 8954.

134. Caratzoulas, S.; Davis, M. E.; Gorte, R. J.; Gounder, R.; Lobo, R. F.; Nikolakis, V.; Sandler, S. I.; Snyder, M. A.; Tsapatsis, M.; Vlachos, D. G.; J. Phys. Chem. C 2014, 118, 22815.

135. Brand, S. K.; Labinger, J. A.; Davis, M. E.; ChemCatChem 2016, 8, 121.

136. Osmundsen, C. M.; Holm, M. S.; Dahl, S.; Taarning, E.; Proc. R. Soc. A 2012, 468, 2000.

137. Li, Y.-P.; Head-Gordon, M.; Bell, A. T.; ACS Catal. 2014, 4, 1537.

138. Bermejo-Deval, R.; Assary, R. S.; Nikolla, E.; Moliner, M.; Roman-Leshkov, Y.; Hwang, S. J.; Palsdottir, A.; Silverman, D.; Lobo, R. F.; Curtiss, L. A.; Davis, M. E.; Proc. Natl. Acad. Sci. USA 2012, 109, 9727.

139. Christianson, J. R.; Caratzoulas, S.; Vlachos, D. G.; ACS Catal. 2015, 5, 5256.

140. Bermejo-Deval, R.; Gounder, R.; Davis, M. E.; ACS Catal. 2012, 2, 2705.

141. Bermejo-Deval, R.; Orazov, M.; Gounder, R.; Hwang, S. J.; Davis, M. E.; ACS Catal. 2014, 4, 2288.

142. Chidambaram, M.; Bell, A. T.; Green Chem. 2010, 12, 1253.

143. Jae, J.; Zheng, W.; Karim, A. M.; Guo, W.; Lobo, R. F.; Vlachos, D. G.; ChemCatChem 2014, 6, 848.

144. Van de Vyver, S.; Geboers, J.; Schutyser, W.; Dusselier, M.; Eloy, P.; Dornez, E.; Seo, J. W.; Courtin, C. M.; Gaigneaux, E. M.; Jacobs, P. A.; Sels, B. F.; ChemSusChem 2012, 5, 1549.

145. Geboers, J.; Van de Vyver, S.; Carpentier, K.; Jacobs, P.; Sels, B.; Chem. Commun. 2011, 47, 5590.

146. Geboers, J.; Van de Vyver, S.; Carpentier, K.; de Blochouse, K.; Jacobs, P.; Sels, B.; Chem. Commun. 2010, 46, 3577.

147. Geboers, J.; Van de Vyver, S.; Carpentier, K.; Jacobs, P.; Sels, B.; Green Chem. 2011, 13, 2167. 
148. Van de Vyver, S.; Geboers, J.; Dusselier, M.; Schepers, H.; Vosch, T.; Zhang, L.; Van Tendeloo, G.; Jacobs, P. A.; Sels, B. F.; ChemSusChem 2010, 3, 698.

149. Bui, L.; Luo, H.; Gunther, W. R.; Roman-Leshkov, Y.; Angew. Chem., Int. Ed. 2013, 52, 8022.

150. Gilkey, M. J.; Panagiotopoulou, P.; Mironenko, A. V.; Jenness, G. R.; Vlachos, D. G.; Xu, B.; ACS Catal. 2015, 5, 3988.

151. Su, Y.; Chang, G.; Zhang, Z.; Xing, H.; Su, B.; Yang, Q.; Ren, Q.; Yang, Y.; Bao, Z.; AlChE J. 2016.

152. Osatiashtiani, A.; Lee, A. F.; Brown, D. R.; Melero, J. A.; Morales, G.; Wilson, K.; Catal. Sci. Technol. 2014, 4, 333.

153. Yang, Y.; Xiang, X.; Tong, D.; Hu, C.; Abu-Omar, M. M.; Bioresour. Technol. 2012, 116, 302.

154. Swift, T. D.; Nguyen, H.; Erdman, Z.; Kruger, J. S.; Nikolakis, V.; Vlachos, D. G.; J. Catal. 2016, 333, 149.

155. Instituto Brasileiro de Geografia e Estatística (IBGE); Levantamento Sistemático da Produção Agrícola; IBGE: Rio de Janeiro, 2012.

156. Tate \& Lyle PLC; Annual Report 2016; Tate \& Lyle PLC: London, 2016.
157. Gallo, J. M. R.; Bueno, J. M. C.; Schuchardt, U.; J. Braz. Chem. Soc. 2014, 25, 2229.

158. Reinikainen, M.; Thomas, D.; Simell, P.; Hannula, I. In Biorefinery I: Chemicals and Materials from Thermo-Chemical Biomass Conversion and Related Processes; Abatzoglou, N.; Kersten, S.; Meier, D., eds.; ECI Symposium Series: Chania, Greece, 2015.

159. Reinikainen, M.; Thomas, D.; VTT Group: http://www. vttresearch.com/Impulse/Pages/Biobased-aromatics-essentialto-the-fine-chemical-industry.aspx, 2015.

160. Michel, H.; Angew. Chem., Int. Ed. 2012, 51, 2516.

161. Horta Nogueira, L. A.; Moreira, J. R.; Schuchardt, U.; Goldemberg, J.; Energy Policy 2013, 61, 595.

162. Schuchardt, U.; Franco, T. T.; de Melo, J. C. P.; Cortez, L. A. B.; Biofuels, Bioprod. Biorefin. 2014, 8, 151.

163. Cortez, L. A. B.; Nigro, F. E. B.; Nogueira, L. A. H.; Nassar, A. M.; Cantarella, H.; Moraes, M. A. F. D.; Leal, R. L. V.; Franco, T. T.; Schuchardt, U. F.; Baldassin Jr., R.; IJAE 2015, 2015, 12.

Submitted: October 17, 2016 Published online: January 30, 2017 